Short abstract: 90 words

Long abstract: 227 words

Main text: 13,150 words

References: 6,045 words

Entire text: 19,636 words

\title{
Why Imaginary Worlds?
}

The psychological foundations and cultural evolution of fictions with imaginary worlds

\author{
Edgar Dubourg \\ Ecole Normale Supérieure-PSL \\ (29 rue d'Ulm, Paris, France) \\ Jean Nicod Institute (ENS, EHESS, CNRS) \\ edgar.dubourg@gmail.com \\ https://edgardubourg.fr \\ Nicolas Baumard \\ Ecole Normale Supérieure-PSL \\ (29 rue d'Ulm, Paris, France) \\ Jean Nicod Institute (ENS, EHESS, CNRS) \\ nbaumard@gmail.com \\ https://nicolasbaumards.org
}

Short abstract: Why do fiction makers spend much time and money inventing imaginary worlds? Why are fictions with such imaginary worlds so successful? Current views in cultural evolution do not explain this massive cultural phenomenon. We argue that imaginary worlds tap into exploratory preferences which have evolved in a wide range of species to propel individuals toward new environments. After reviewing research on exploratory behaviors and preferences, we argue that this hypothesis explains the way imaginary worlds evolved culturally, their recent striking success, their shape and their distribution across time and populations.

Long abstract: Imaginary worlds are extremely attractive. The most culturally successful fictions produced in the last decades contain such a fictional world. They can be found in all fictional media, from novels (e.g., Lord of The Ring, Harry Potter, The Chronicles of Narnia) to films (e.g., Star Wars), video games (e.g., The Legend of Zelda), graphic novels (e.g., One piece, Naruto) and TV series (e.g., Star Trek, Game of Thrones), and they date as far back as ancient literature (e.g., the Cyclops Islands in The Odyssey, $850 \mathrm{BCE}$ ). Why such a success? Why so much attention devoted to nonexistent worlds? In this article, we propose that imaginary worlds co-opt our preferences for spatial exploration, which have evolved in humans and non-human animals alike to propel individuals toward 
new environments. Humans find imaginary worlds very attractive for the very same reasons, and under the same circumstances, as they are lured by unknown and unfamiliar environments in real life. After reviewing research on exploratory behaviors and preferences in behavioral ecology, environmental aesthetics, neuroscience and evolutionary psychology, we identify a cognitive bias for novel environments. We argue that this content bias has shaped the cultural evolution of imaginary worlds. This hypothesis explains the massive success of fictional devices such as maps, props, paratexts and adventurous protagonists, as well as the cultural distribution of fictions with imaginary worlds across time, space and population.

Keywords: cognitive attraction, cultural evolution, curiosity, exploration, fiction, imaginary worlds, novelty, reward

\section{Introduction}

The world around, fictions with imaginary worlds draw acclaim from the public, the critics and the industry, making them both best-selling and most-appreciated fictions (e.g.., top-ranked in online ranking websites). For instance, The Lord of the Ring novels are among the best-selling novels ever written, with more than 150 million copies sold in 38 different languages. The screen adaptations by Peter Jackson grossed each around 1 billion dollars in box-office worldwide, making them among the highest-grossing films ever produced. They received universal critical acclaim and won 17 Academy Awards. The Return of the King alone won 11 of them, setting the current record of the most Oscars won by a single movie. This sequel is the $5^{\text {th }}$ film in the "all-time top-rated movies" list from IMDb, the biggest user-generated ranking dataset on films. Producers of fictions know just how lucrative this kind of fiction can be: after a competitive bid against HBO and Netflix, Amazon bought the rights to produce TV programs based on Tolkien's imaginary world for 250 million dollars, which is by far the most expensive script idea ever sold. Tolkien's world has also been adapted into theatre, radio, board games, video games and role-playing games (e.g., Dungeon and Dragons and Middle-Earth Role Playing).

Many other fictions can be mentioned: Star Wars, the most successful fiction merchandising franchise of all time (Block \& Wilson, 2010) and the most influential movie in the history of films (Canet, 2016); Harry Potter, the best-selling book series in history, translated into 80 languages; Game of Thrones, whose final episode set the all-time audience record for a TV series with 16,4 million 
people watching it live and 15 million people streaming it later; The Legend of Zelda, one of the bestselling video game series worldwide, with over 100 millions video games sold since the first one; and the Marvel Cinematic Universe, a shared imaginary world derived from a series of super hero films with common settings and characters, which cumulates several records in the history of cinema, including the highest opening week gross (Avengers: Endgame), the biggest opening week-end (Avengers: Infinity $W a r$ ) and, more significatively, the highest-grossing movie of all time (Avengers: Endgame). A more quantitative approach confirms these remarks: the numbers of speculative novels (Figure 1) and the number of speculative films (Figure 2) have considerably increased in the last hundred years (Dubourg, Thouzeau, et al., 2021).
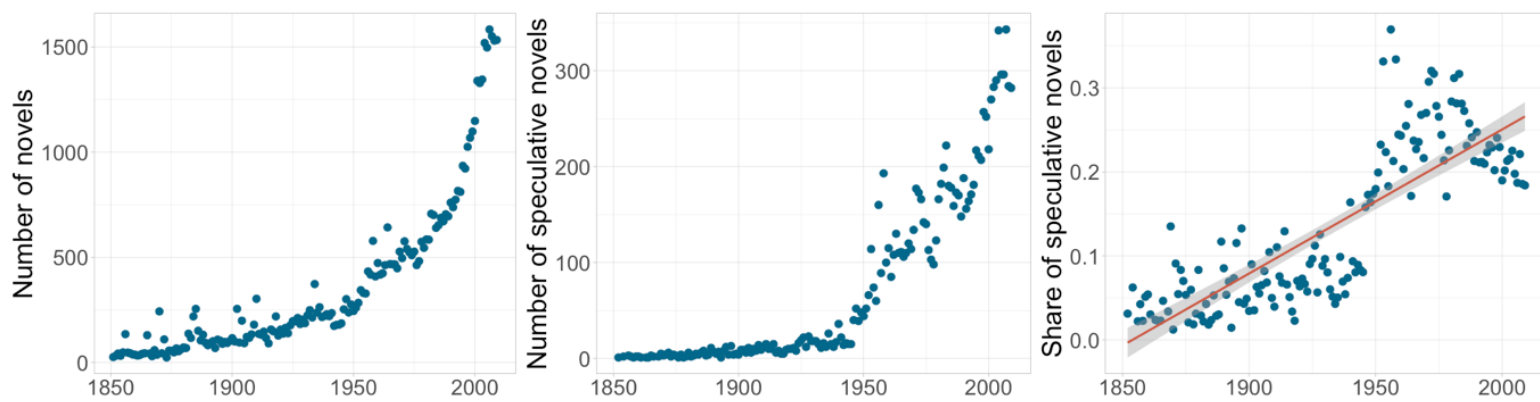

Figure 1. The evolution of the number of speculative novels, as a proxy for the evolution of fictions with imaginary worlds, with data of literary works from 1850 to 2000, extracted from Wikidata (N=96,711). For each novel, the following variables were extracted: the title, the year of publication and the genres. After removing genres that appeared less than 10 times in the dataset, 25 genres (out of the remaining 239 genres) were identified as fitting the category of speculative fiction (see Table 1). A. The evolution of the number of novels published per year. B. The evolution of the number of speculative novels published per year. C. The evolution of the share of speculative novels published per year. A linear model estimates a significative effect of time on the share of speculative novels: $\beta=1.715 \mathrm{e}-03$, $\mathrm{p}<2 \mathrm{e}-16$, adjusted $\mathrm{R}^{2}=0.6696$ (Dubourg, Thouzeau, et al., 2021).
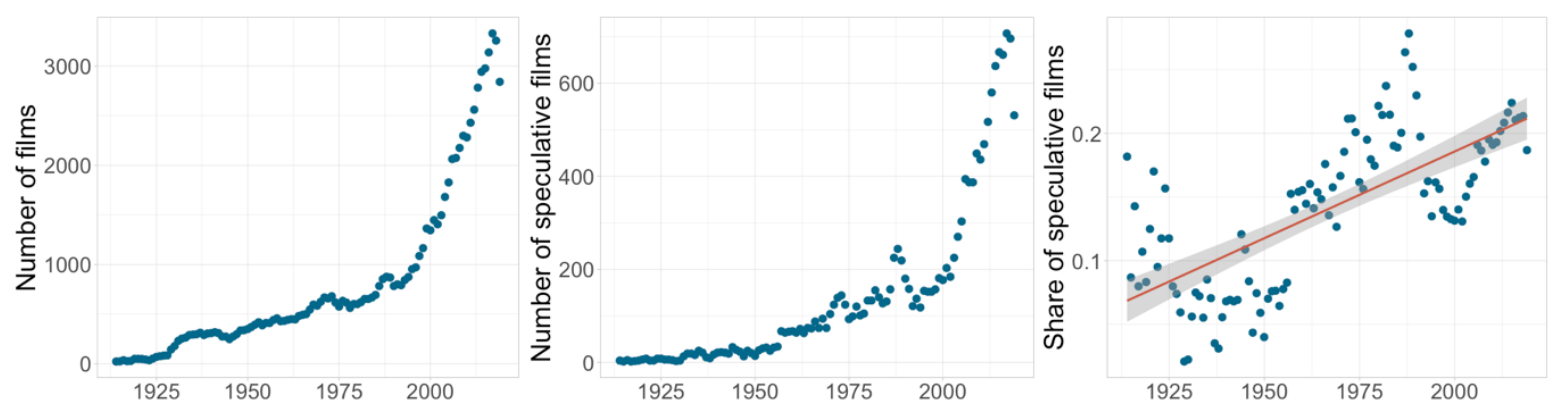

Figure 2. The evolution of the number of speculative films, as a proxy for the evolution of fictions with imaginary worlds, with data of films from 1913 to 2020, extracted from IMDb (N=85,855). For each film, the following variables were extracted: the title, the year of release and the genres. 5 genres (out of the 21 genres) were identified as fitting the category of speculative fiction (see Table 1). A. The evolution of the number of films released per year. B. The evolution of the number of speculative films released per year. C. The evolution of the share of speculative films released per year. A linear model estimates a significative effect of time on the share of speculative films: $\beta=0.0013642, \mathrm{p}<2 \mathrm{e}-16$, adjusted $\mathrm{R}^{2}=0.4897$ (Dubourg, Thouzeau, et al., 2021). 
The examples of The Lord of the Ring, Star Wars and Harry Potter are startling, because they are without any doubt the most popular fictions worldwide and, at the same time, the fictions which may have pushed the building of imaginary worlds the furthest in terms of innovative settings. In cultural studies, it has been argued that "more and more, storytelling has become the art of worldbuilding, as artists create compelling environments that cannot be fully explored or exhausted within a single work or even a single medium" (Jenkins, 2006, p. 117; see also Besson, 2015; Wolf, 2013). This goes to the point that imaginary worlds without any narrative have become to appear. One compelling example is the Codex Serapbinianus, an encyclopedia of an imaginary world with no story nor protagonist (Luigi Serafini, 1981). Imaginary worlds are also invading mainstream literature with novels like The Possibility of an Island by Michel Houellebecq which blurs the lines between science-fiction, alternative history and highbrow general fiction.

This cultural phenomenon is not at all limited to the United-States and the English-speaking Western countries. Harry Potter, Star W ars and The Lord of the Rings are highly popular all around the world and in fact, these franchises make most of their revenues outside North America (Kuipers \& de Kloet, 2009). Also, many imaginary worlds produced and consumed all around the world are produced outside the English-speaking world. One can cite the critically acclaimed Belgian comic book Thorgal, with its 11 million printed books sold; Pierre Boulle's French novel Planet of the Apes, and its famous adaptations to the screen; the Japanese manga One Piece, which has become the bestselling manga series in history with its 470 million copies sold in 43 different countries; and Liu Cixin's The Three-Body Problem, the most famous science fiction novel in China and the first Asian novel to win the Hugo Award.

Steven Pinker once wrote that, because they often follow their personal tastes, literary critics study fictions that appeal to $1 \%$ of the population (Pinker, 2007). Here, we aimed at studying fictions that appeal to the majority, everywhere. In this sense, a psychological and evolutionary understanding of the appeal for imaginary worlds is long overdue.

\section{Imaginary worlds and world-dominant fictions}

Fictions differ in the degree to which they distinguish themselves from the real world. For instance, in Balzac's novels, the fictional environment depicted is identical to France from the author's period and, while Balzac added approximately 3,000 fictional individuals, we intuitively picture the protagonists within the real world (Pavel, 2017). We infer much information derived from our 
knowledge of the real world, such as the country in which the fiction takes place, its geography, its political institutions and the technology. In fiction study, this is known as the "principle of minimal departure" (Ryan, 1991; Searle, 1975) or "reality principle" (Pavel, 2017; Walton, 1993). Conversely, Tolkien's "subcreated" world is ostentatiously different from any environment in the real world (Tolkien \& Tolkien, 2006).

Following these examples, the key determinant of our definition of an imaginary world is the background knowledge required to understand the fiction: imaginary worlds are defined as fictional environments that the recipients of the fiction could not have possibly explored in real life, be it far removed islands, locations in the future or the distant past, other planets or environments in alternative history. In fact, in the example of Tolkien, the background information, is commonly considered by literary critics as the most important one. In 1956, Tolkien wrote a letter which shows the crucial interest of his readers for background information:

Most people want more (and better) maps; some wish more for geological indications than place-names; many want more specimens of Elvish, with structural and grammatical sketches; others ask for metrics and prosodies, not only of the Elvish, but of the "translations" that are in unfamiliar modes—such as those composed in the strictest forms of Anglo-Saxon verse (e.g., the fragment on the Battle of Pelennor, Book. Five, vi, 124). Musicians want tunes and musical notations. Archaeologists enquire about ceramics, metallurgy, tools and architecture. Botanists desire more accurate descriptions of the mallorn, of elanor, niphredil, alfirin and mallos, and of symbelmyne. (...) Historians require more details about the social and political structure of Gondor, and the contemporary monetary system. (Letter to H. Cotton Minchin, 16 April 1956).

Therefore, by definition, a fiction based on an imaginary world is a fiction in which the consumer will learn a lot of novel information about the fictional environment (also called the 'chronotope' in literary theory and philosophy of language; Bakhtin \& Emerson, 1984). For example, Harry Potter has Hogwarts and many other magical locations, Jules Verne's From the Earth to the Moon has the Moon (which had obviously not yet been explored at the time of the author), the Odyssey has the Cyclops Islands, Aiaia, the Fortunate Islands, the Siren Island and the Lotophages, to name only a few invented locations, and The Lord of the Ring is set in a complex alternate world with hundreds of invented locations. It is worth noting that religious narratives also involve unknown worlds that are, in a way, imaginary, with different physical laws and spatial structures. However, religious narratives cannot be considered as fictions. In this paper, we will limit our study to fictional worlds, 
mostly because non-fictional worlds such as religious worlds are likely to be culturally stabilized for reasons (e.g., authority) that differs from pure entertainment (Boyer, 2001).

\begin{tabular}{|c|c|c|}
\hline Genre & Definition & Examples \\
\hline Fantasy & $\begin{array}{l}\text { Includes elements and beings originating from or in- } \\
\text { spired by traditional stories, such as mythical crea- } \\
\text { tures (dragons, elves, dwarves and fairies, for exam- } \\
\text { ple), magic, witchcraft, potions, etc. }\end{array}$ & $\begin{array}{l}\text { The Lord of the Rings, Dungeons and } \\
\text { Dragons, The Legend of Zelda, Harry } \\
\text { Potter, A Song of Ice and Fire, Magic: } \\
\text { The Gathering, Kafke on the Shore, } \\
\text { World of W arrraft }\end{array}$ \\
\hline $\begin{array}{l}\text { Science fic- } \\
\text { tion }\end{array}$ & $\begin{array}{l}\text { Features technologies and other elements that do not } \\
\text { exist in real life but may be supposed to be created or } \\
\text { discovered in the future through scientific advance- } \\
\text { ment, such as advanced robots, interstellar travel, al- } \\
\text { iens, time travel, mutants and cyborgs. }\end{array}$ & $\begin{array}{l}\text { The Time Machine, I, Robot, Dune, } \\
\text { Star Trek, 2001: A Space Odyssey, } \\
\text { Swamp Tbing, Black Mirror, Star } \\
\text { Wars, Blade Runner, Jurassic Park, } \\
\text { The Hitchbiker's guide to the galaxy }\end{array}$ \\
\hline $\begin{array}{l}\text { Adventure } \\
\text { fictions }\end{array}$ & $\begin{array}{l}\text { Features a fast-paced, action-packed plot in which } \\
\text { the hero has to complete a quest or a task. The ad- } \\
\text { venture story usually takes place elsewhere, and uses } \\
\text { maps, intriguing backgrounds to interest the reader. }\end{array}$ & $\begin{array}{l}\text { The Odyssey, Gulliver's Travels, Robin- } \\
\text { son Crusoe, The Jungle Book, Treasure } \\
\text { Island, Two Years' Vacation, Michel } \\
\text { Strogoff, Lord of the Flies, Up, The } \\
\text { Revenant }\end{array}$ \\
\hline Uchronia & $\begin{array}{l}\text { Focuses on historical events as if they happened in a } \\
\text { different way, and their implications in the present. }\end{array}$ & $\begin{array}{l}\text { The Man in the High Castle, The Last } \\
\text { Starship from Earth, Once Upon a } \\
\text { Time... in Hollywood }\end{array}$ \\
\hline Utopian & $\begin{array}{l}\text { Takes place in a highly desirable society, often pre- } \\
\text { sented as advanced, happy, intelligent or even perfect } \\
\text { or problem-free. }\end{array}$ & $\begin{array}{l}\text { Utopia, Island, Ecotopia, 17776, A } \\
\text { Modern Utopia, Men Like Gods, Euto- } \\
\text { pia }\end{array}$ \\
\hline Dystopian & $\begin{array}{l}\text { Takes place in a highly undesirable society, often } \\
\text { plagued with strict control, violence, chaos, brain- } \\
\text { washing or other negative elements. }\end{array}$ & $\begin{array}{l}\text { Brave New World, 1984, The Hand- } \\
\text { maid's Tale, A Clockwork. Orange, The } \\
\text { Hunger Games }\end{array}$ \\
\hline Superhero & $\begin{array}{l}\text { Centers on superheroes (i.e., heroes with extraordi- } \\
\text { nary abilities or powers) and their fight against evil } \\
\text { forces such as supervillains. }\end{array}$ & $\begin{array}{l}\text { DC Universe, Marvel Cinematic } \\
\text { Universe, Naruto, Kamen Rider, X- } \\
\text { Men, Super Sentai, Power Rangers }\end{array}$ \\
\hline Supernatural & $\begin{array}{l}\text { Exploits as plot devices or themes some contradic- } \\
\text { tions of the commonplace natural world and materi- } \\
\text { alist assumptions about it. }\end{array}$ & $\begin{array}{l}\text { The Castle of Otranto, Stranger Things, } \\
\text { Paranormal Activity, Dark, Fallen, } \\
\text { The V ampire Diaries, Charmed }\end{array}$ \\
\hline Apocalyptic & $\begin{array}{l}\text { Takes place before and during a massive, worldwide } \\
\text { catastrophe. }\end{array}$ & $\begin{array}{l}\text { On the Beach, Threads, The Day After } \\
\text { Tomorrow, 2012, World War Z }\end{array}$ \\
\hline $\begin{array}{l}\text { Post-apoca- } \\
\text { lyptic }\end{array}$ & $\begin{array}{l}\text { Focuses on groups of survivors after massive world- } \\
\text { wide disasters. }\end{array}$ & $\begin{array}{l}\text { The Stand, Mad Max, Waterworld, } \\
\text { Fallout, Metroid Prime, Metro } 2033 \text {, } \\
\text { The Walking Dead }\end{array}$ \\
\hline
\end{tabular}

Table 1. Fictional genres of the broad category of speculative fictions, conducive to the building of imaginary worlds, with the definitions from Wikipedia and some examples.

Fictions with imaginary worlds are not the only fictions in which the background information is central. One could also mention historical novels such as Umberto Eco's The Name of the Rose and social realistic novels such as Zola's Germinal where the environment, be it a medieval Benedictine monastery or as industrial mine complex, plays a central role in the fiction. Thus, fictions with imaginary worlds belong to the broader category of world-dominant fictions, as opposed to storydominant fictions (Ryan, 2017). It is also important to note that our definition of fictions based on imaginary worlds is very close to the category of "speculative fictions", which encompasses any 
fictional genre typically containing some background elements that do not exist in the real world (Table 1) but does not totally overlap with it. Indeed, not all speculative fictions require extensive background information to be appreciated. For instance, Edgar Poe's and Franz Kafka's fantastic tales in which there is only one element of supernatural do not offer much to explore; the appeal of these fictions relies on the blurring of the boundaries between what is real and what is unreal (Todorov, 2015). That being said, we will consider that the broad category of speculative fictions is a good proxy for fictions with imaginary worlds.

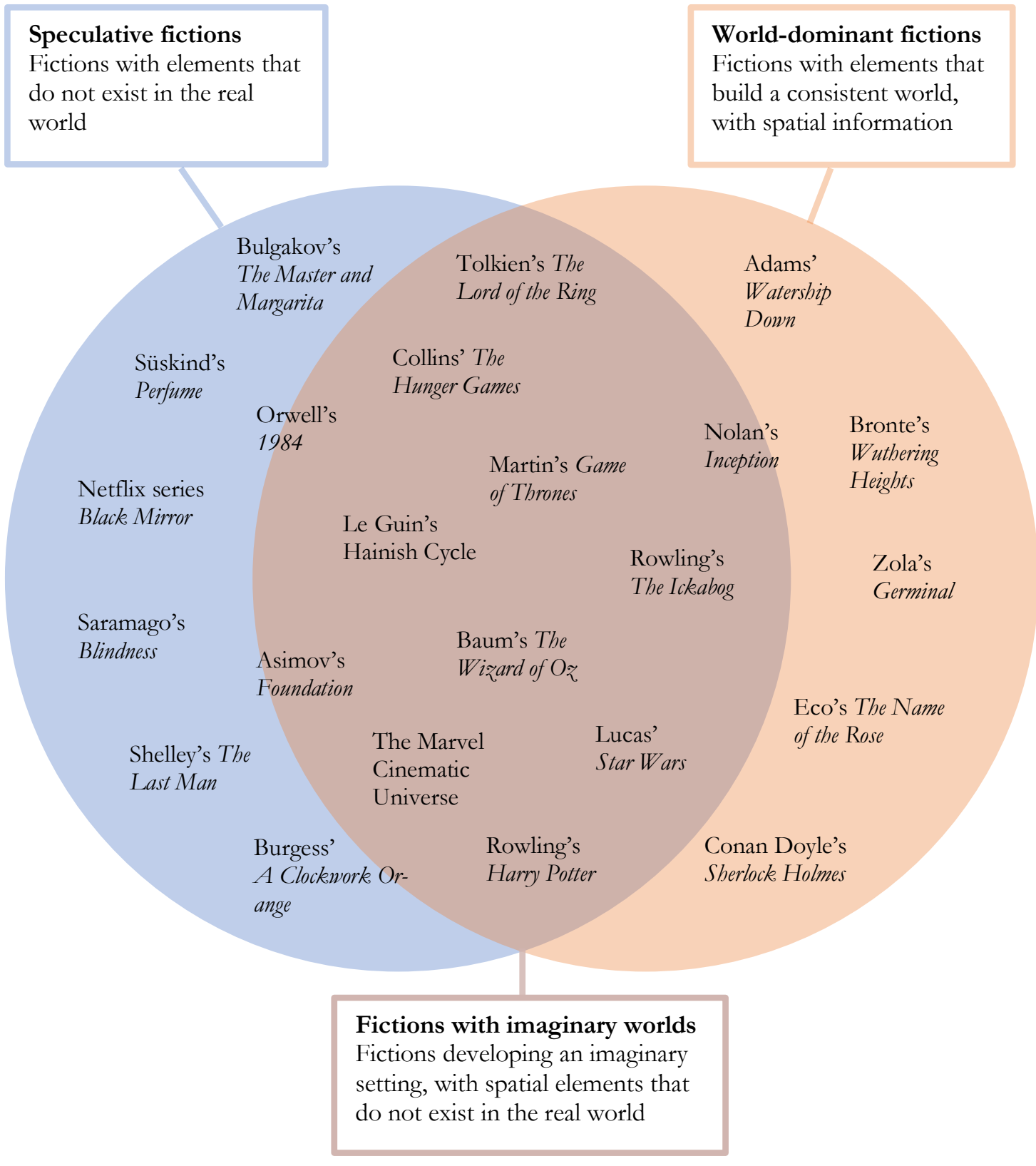

Figure 3. Fictions with imaginary worlds consist in the large intersection of speculative fiction and world-dominant fictions. 
Fantasy and science fiction are recent fictional genres, but the history of fictions shows much more diversity than this classification suggests (Scholes \& Rabkin, 1977). A huge number of ancient fictions set an imaginary world, in ancient epic poems about heroes' journeys, travelers' tales from the exploration age, adventure fictions, utopias and dystopias. For instance, the ancient Mesopotamian The Epic of Gilgamesh (1800 BCE) and The Odyssey (850 BCE) are often mentioned as precursors of fantasy fiction. Some scholars have tried to map the faraway lands and islands visited by Odysseus (Clay, 2007). Other imaginary locations from this period were directly described without any narration (e.g., Arimaspi, the imaginary world from Herodotus' Histories). Lucian of Samosata's True History is a proof that travelers' tales from this ancient period were considered as imaginary by their audience, as the author makes it clear about his own story and others, in the introduction: "I see no reason for resigning my right to that inventive freedom others enjoy [...]. My subject is, then, what I have neither seen, experienced, nor been told, what neither exists nor could conceivably do so. I humbly solicit my readers' incredulity.” (Lucian of Samosata, 150 C.E.). Other imaginary worlds are mentioned to strengthen this argument (Table 2).

\begin{tabular}{l|llll}
\hline \hline Location name & Title & Author & Date & Region \\
\hline \hline Anpu's Country & Tale of Two Brothers & Undetermined & 1200 BCE* & Egypt \\
\hline Odysseus Islands & The Odyssey & Homer & 900 BCE* & Greece \\
\hline Islands of the Sun & Islands of the Sun & Iambulus & 100 BCE* & Greece \\
\hline Island of Anostus & Varia Historia & Claudius Aelianus & $175^{*}$ & Rome \\
\hline The Otherworld & The Voyage of Bran & Undetermined & $750^{*}$ & Ireland \\
\hline Magical islands & Sinbad the Sailor & Undetermined & $800^{*}$ & Middle East \\
\hline The Moon & The Tale of the Bamboo Cutter & Undetermined & $950^{*}$ & Japan \\
\hline Brocéliande & Yvain, the Knight of the Lion & Chrétien de Troyes & 1180 & France \\
\hline Cockaigne & Le Dit de Cocagne & Undetermined & $1250^{*}$ & France \\
\hline Hell & The Divine Comedy & Dante & 1321 & Italy \\
\hline $\begin{array}{l}\text { Devil's Island and } \\
\text { other islands }\end{array}$ & Amadís de Gaule & Undetermined & 1508 & France \\
\hline Utopia & Utopia & Thomas More & 1516 & England \\
\hline Prospero's Island & The Tempest & William Shakespeare & 1623 & England \\
\hline $\begin{array}{l}\text { Lilliput, Laputa, } \\
\text { Brobdingnag, etc. }\end{array}$ & Gulliver's Travels & Jonathan Swift & 1726 & Ireland \\
\hline \hline
\end{tabular}

Table 2. Examples of imaginary worlds in non-contemporary fictions, with their invented toponyms, extracted from the broadly inclusive list of imaginary worlds put forward by Mark J.-P. Wolf (* Dates are approximative).

All this suggests that, in fictions, imaginary worlds are highly appealing, and more and more so. It raises many questions. Why this urge to create new locations from scratch? The same stories could take place in faithful representations of the real world and, in the case of films, for instance, it would considerably reduce the costs of fiction making. Why are we captivated by fictions with imaginary worlds, and seemingly more and more so? This suggests that we are more and more predisposed to appreciate such fictions, otherwise, we would have invented more imaginary worlds 
much earlier. Why are best-rated video games those with large open worlds (e.g., Zelda, Assassin's Creed, No Man's Sky)? Why Baum (The Wizard of O₹), Tolkien (The Lord of the Ring), Lucas (Star Wars), Cameron (Avatar), Rowling (Harry Potter) and developers from Hello Games Studio (No Man's Sky), to name only a few, were willing to devote multiple years of their lives developing an imaginary world, and why is it rewarding and interesting to us? In a nutshell: why imaginary worlds?

\section{The psychological foundations and cultural evolution of fictions}

Why do human produce and consume fiction? In this article, we adopt an evolutionary framework according to which producing and consuming art work can be adaptive for both the producers and the consumers (André et al., 2020; Mehr et al., 2020; Tooby \& Cosmides, 1992). Standard evolutionary approaches to fiction have noted the fitness benefits of producing fictions in terms of sexual signaling (Miller, 2001) but also in terms of social signaling toward potential cooperative partners through the production of entertaining devices (Nettle, 2005b; Singh, 2019, 2020). But there are also multiple benefits in consuming fictions, such as using fiction consumption to signal ones' preferences, skills, qualities and other human capitals (André \& Baumard, 2020; Bourdieu, 1979; Veblen, 1899), as well as to share cultural focal points for social interactions, social gathering and communication (Dubourg, André, et al., 2021b, 2021a).

This evolutionary approach to fiction puts forward the idea that fictions are functional in that they attract people's attention, and this gives rise to a range of adaptive opportunities such as signaling opportunities (Dubourg, André, et al., 2021b, 2021a). This explains why culturally successful fictions tend to recycle and exaggerate the most attention-grabbing and fitness-relevant events in real life (Boyd, 2018; Carroll, 2012; Gottschall, 2012; Gottschall \& Wilson, 2005; Mar \& Oatley, 2008; Saad, 2012; Schaeffer, 1999), such as romantic relationship (Alberti, 2013; Cox \& Fisher, 2009; Salmon \& Symons, 2004; Vanderbeke, 2019), cooperation and cheating (Singh, 2019), social status (Nettle, 2005a, 2005b) and political rivalries (Jobling, 2001). In other words, fictions constitutes 'intensified stimuli' or 'superstimuli' in the sense that they are crafted to artificially grab the consumers' attention, just like masks artificially trigger the human face detection capacity, and cuisine artificially triggers the nutrients detector systems (Boyer, 2018; Buss, 2015; Nettle, 2005a; Sperber, 1996; Sperber \& Hirschfeld, 2004; Verpooten \& Nelissen, 2010). Triggering people's attention is indeed the most important element of success for both producers and consumers, who want to produce and consume fictions that are likely to also attract the attention of the individuals that matter to them. 
Such an evolutionary and cognitive approach of fiction therefore predicts that to answer the question "Why do people enjoy fictions?" is very close to answering the question "Why do people enjoy life?” (Bloom, 2010; Pinker, 1997). While previous evolutionary approaches to fiction have focused on preferences involved in story-dominant fictions, we focus here on one preference, i.e., the preference for exploration, which is involved in world-dominant fictions, and in particular in imaginary worlds. Indeed, in this article, we propose that imaginary worlds co-opt our evolved exploratory preferences. Humans find imaginary worlds very attractive for the very same reasons, and under the same circumstances, as they are lured by unknown and unfamiliar environments in real life. Obviously, fictions tap into many kinds of human interests and our paper is about just one of them. Thus, our paper does not suggest that everybody should like imaginary worlds. A parallel can be made with cuisine: sugar is clearly an important cultural attractor in the cultural evolution of recipes, but not all recipes include sugar and not everybody likes candies and pastries. In other words, while some people prefer consuming fictions about familiar places and comforting stories, others seem to enjoy exploration, and they preferably consume fictions about new and mysterious places.

It is worth noting that this framework departs from other evolutionary views according to which fictions are used to convey and teach new information (Sugiyama, 1996, 2001) or to simulate the real world (Mar \& Oatley, 2008; Morin et al., 2019). Here we rather assume that fictions are mostly produced to trigger pleasure and attract people's attention because doing so leads to a lot of social opportunities (e.g., signaling, coordinating). Thus, we do not hypothesize that there is any specific value in the information included in The Lord of the Rings or in Harry Potter. These fictions, with their imaginary worlds, are enjoyed by people because they meet the 'input conditions' of their cognitive dispositions geared toward exploration, just as masks meet the input condition of the human's face detection module (Sperber \& Hirschfeld, 2004). Because fiction makers exaggerate the usefulness of such information in the fictions, it grabs our attention, whether or not this information is useful in the real world.

\section{The evolution and psychology of exploratory preferences}

Our hypothesis is that preferences for imaginary worlds rely on exploratory preferences, driving our motivation to explore novel environments. As Tolkien put it himself, "part of the attraction of The Lord of the Rings", and other fictions with imaginary worlds, relies on the intrinsic feeling of reward we experience when "viewing far off an unvisited island or the towers of a distant city" (letter to Colonel Worskett, 20 September 1963). This statement is very close to the one of Shigeru 
Miyamoto, the creator of Zelda, who reported that he "wanted to create a game world that conveyed the same feeling you get when you are exploring a new city for the first time" (1989). Such fictions would thus "tap into that deeply-seated human desire to travel, seek out new experiences, and absorb new knowledge about the world" (Etchells, 2019). In this section, we explain further the ultimate and proximate mechanisms behind exploratory preferences.

\subsection{The evolution of exploratory preferences: the fitness benefits of spatial exploration}

From an evolutionary point of view, there is a broad consensus that exploring the environment is especially adaptive for mobile species, as it leads to discovering new vital resources such as food, finding mates and habitats, avoiding predators and learning new action-outcome associations (Cashdan \& Gaulin, 2016; Chambon et al., 2018; Gottlieb \& Oudeyer, 2018; Hayden \& Niv, 2020; Hewlett et al., 1982; T. T. Hills, 2006; MacDonald \& Hewlett, 1999; Miner et al., 2014; Panksepp, 2005). For many species in many ecologies, such benefits outweigh the costs of exploration (e.g., energetic, economic, injury and opportunity costs). Humans were not untouched by this selection pressure stemming from such an exploitation-exploration trade-off. Long-distance dispersal have been an important component of human migrations, allowing fast colonization of new territories all over the planet (Alves et al., 2016). Moreover, during the majority of their evolutionary history, Homo Sapiens led a nomadic way of life (Lee, 1966), not unlike many other species who are known to travel across space (Chapman et al., 2014).

In line with the idea that there are fitness benefit for spatial exploration, studies have shown that non-human animals are endowed with specific capacities to explore their environment, recall the location of resources, determine the best navigation route between resources, and reorient when approaching locations from new perspectives (Rosati \& Hare, 2012). Importantly, these capacities vary according to the ecology of the species (Healy et al., 2005; Platt \& Brannon, 1996; Rosati et al., 2014). For instance, chimpanzees exhibited more accurate spatial memory than bonobos across contexts, supporting predictions from these species' different feeding ecologies: wild chimpanzees depend more on patchily distributed fruit, whereas bonobos depend more on homogeneously distributed resources such as terrestrial herbaceous vegetation (Rosati \& Hare, 2012). Fishes' spatial behavior too is very flexible, and this plasticity would rely on homologous cognitive mechanisms as those identified in mammals and birds (Broglio et al., 2003). Importantly, these adaptations are not limited to purely cognitive capacities, they also extend to reward orientation. For instance, tamarins who feed on an ephemeral, dispersed food source (e.g., insects) and travel through large territories are much more likely to travel to a smaller, closer reward or a larger, more distant reward 
than marmosets who feed on a localized, immobile food (gum and sap exuding from trees) and, consequently, face little pressure to travel long distances for food (Stevens et al., 2005).

Finally, it is important to note that such cognitive capacities are hypothesized to be the evolutionary precursor to goal-directed cognition: many disciplines ranging from behavioral ecology to molecular genetics provide evidence that, for instance, problem-solving is a cognitive system born out ancient space foraging behaviors (T. T. Hills, 2006; T. T. Hills et al., 2010; T. T. Hills \& Stroup, 2004). Such capacities are shared across all mobile organisms. Fishes' spatial behavior, for instance, is as elaborate as the ones of land vertebrates (Broglio et al., 2003). Even further away from humans in the phylogenetic tree, bacteria's attempts to go back to resourceful environments through turns after removal from food is a strategic foraging behavior (Korobkova et al., 2004; Neidhardt \& Curtiss, 1996). In humans, cognitive maps are applied to non-spatial domains such as conceptual thinking (Behrens, 2018; Epstein et al., 2017; Jacobs, 2003), and exploratory preferences are rallied to domain-general decision-making processes (Daw et al., 2006; T. T. Hills et al., 2010; Le Heron et al., 2019). Crucially, there is empirical evidence that preferences for spatial exploration in foraging tasks are correlated with preferences for cognitive exploration in problem-solving tasks ( $\mathrm{T}$. T. Hills \& Stroup, 2004).

4.2 The behavioral manifestations of exploratory preferences: animal exploration, wayfinding and environmental aesthetics

Such preferences for spatial exploration are blatant when studying animal behavior. Many experimental studies revealed how curious about novel environments animals can be. In a famous study, rats were found to spend more time exploring novel environments than exploiting familiar ones (Berlyne, 1950). Since then, the novelty-based theory of exploration has been supported by many studies in the non-human animal literature, with various empirical tests, from the "open-field arena" test for mice (Berlyne, 1970; Peeler \& Nowakowski, 1987) to the "visual novelty preference" test for monkeys and humans (e.g., Fagan, 1970; Gunderson \& Sackett, 1984). Rats can learn to find their way around a maze in the absence of rewards (Byrne, 2013; Reed \& Adams, 1996), suggesting that the opportunity to explore action-outcome relationships is intrinsically rewarding (Polizzi di Sorrentino et al., 2014). Rats and pigeons prefer multiple-choices paths over no-choice, shorter paths leading to the same reward (Bown et al., 2003; Catania, 1980; Catania \& Sagvolden, 1980; McDevitt et al., 2018). More recent studies with two-choice tests showed that animals are more interested by unfamiliar objects compared to familiar ones. At this stage, it has been proved 
to be the case for bottlenose dolphins, Pacific white-sided dolphins, beluga whales (Guarino et al., 2017), rhesus macaques (Englerova et al., 2019; Wang \& Hayden, 2019) and orangutans (Borel et al., 2016). Also, it is worth noting that exploration is still preferred when the payoff is removed: in so-called non-instrumental tasks, animals observe novel stimuli even if they cannot act on them (Gottlieb \& Oudeyer, 2018). More surprisingly, exploration is attractive to the point that animals are willing to pay a supplementary cost to keep exploring (FitzGibbon et al., 2020; Hughes, 2007; Oudeyer et al., 2016).

In humans, one obvious place to look for exploratory preferences are studies of wayfinding. Wayfinding is generally defined as the ability to move around efficiently and find the way from a starting point to a destination (Montello, 2005). It is different from pure locomotion. Locomotion depends on sensory-motor systems interacting with an immediate surrounding, while wayfinding invokes higher-level cognitive systems to maintain orientation relative to the distal environment. Experimental work has shown that performance in wayfinding is predicted by both cognitive capacities (e.g., visuospatial memory, mental rotation ability) and individual preferences. For instance, individuals who take pleasure in exploring places tend to have a good sense of direction (Muffato et al., 2017) and perform better in spatial tasks (Carbone et al., 2020; Muffato et al., 2016, 2017). In particular, Pazzaglia et al. (2018) showed that a significant part of the variability in the performance was explained by an aggregate measure of pleasure in exploring. Interestingly, the strength of the relationship between preferences and wayfinding tasks seems to depend on how difficult the task is: the tougher the task, the stronger the relationship (Pazzaglia et al., 2018; Weisberg et al., 2014).

Another area of research is known as 'environmental aesthetics', a domain of empirical psychological research which investigates the elements of settings to which people are attracted the most (Balling \& Falk, 1982; Falk \& Balling, 2010; T. R. Herzog, 1984, 1985; T. R. Herzog \& Bryce, 2007; T. Herzog \& Smith, 1988; Ikemi, 2005; R. Kaplan \& Kaplan, 1989; S. Kaplan, 1988; Ruso et al., 2003; Ulrich, 1979). Scholars working in environmental aesthetics have conducted a great number of empirical studies based on data collection, so as to investigate the existence and the nature of universal preferences regarding environments. One of the key findings of this research program is that environments and landscapes are typically better rated and thus preferred when the settings signal an opportunity to gather information through exploration (e.g., the picture shows a trail that disappeared around a corner). Therefore, what makes an environmental setting appealing is the promise of further novel information, causally inferred from cues indicating that an enrichment in knowledge is a possibility. It is important to note here that these preferences are said to be 
automatic, unconscious and intuitive. More often than not, participants were unable to explain their choices when rating the landscapes (S. Kaplan, 1987), sustaining the hypothesis that sometimes "preferences need no inferences” nor explicit judgments (Zajonc, 1980).

4.3. The cognitive and neural mechanisms underpinning exploratory preferences: plasticity, the exploitation-exploration trade-off and the dopamine system

The study of wayfinding and environmental preferences demonstrates the existence of specific preferences for spatial exploration. Exploratory preferences are part of a broader set of personality traits related to the meta-trait 'Plasticity'. The trait Plasticity reflects the degree to which an organism is prone "to generating new goals, new interpretations of the present state, and new strategies to pursue existing goals" (DeYoung, 2013, 2015). Behavioral plasticity and exploratory preferences are inseparable notions because spatial exploration requires to be able to flexibly adapt to changing environments, otherwise exploration is too costly (Rojas-Ferrer et al., 2020; Sol et al., 2016). From an empirical perspective, exploratory preferences are best studied through two important constructs that are highly correlated (DeYoung, 2015; George \& Zhou, 2001; Gocłowska et al., 2019; Gottlieb et al., 2013; Li et al., 2014; McCrae, 1993): 1) the Big Five trait Openness to experience in personality psychology (e.g., Carbone et al., 2019, 2020; Meneghetti et al., 2020; Pazzaglia et al., 2018) and 2) novelty-seeking in the neuroscience of decision-making (e.g., Costa et al., 2014; Krebs et al., 2009). It is worth noting that wayfinding inclinations have been shown to be positively associated with Openness to experience (Carbone et al., 2020; Meneghetti et al., 2020).

To further understand how exploratory preferences work at the proximate level, empirical research designed the "bandit" task and its variants (Schulz \& Gershman, 2019): in its most basic design, the learner must choose between pulling a lever with known but degressive reward (i.e., to exploit) or a lever with unknown payoff, which is the exploratory choice (Cohen et al., 2007; Daw et al., 2006; Gershman, 2018; Le Heron et al., 2019). It has been found that humans use a combination of both directed and random exploration strategies, with novelty cues as informative "bonuses" (Chakroun et al., 2020; Gershman, 2018; Gottlieb \& Oudeyer, 2018; Schulz \& Gershman, 2019; R. C. Wilson et al., 2014). The exploitation-exploration trade-off is a classic problem in reinforcement learning. The computational theory of reinforcement learning claims that the high-level goal of any learning agent is to obtain as much reward as possible, even if it is delayed (Dubey \& Griffiths, 2020; Gozli, 2018) and it supports the idea from behavioral ecology that knowledge acquisition, 
prompted by novelty-based exploration, aims at optimizing future rewards (Brändle et al., 2020; Dubey \& Griffiths, 2020; Oudeyer et al., 2016).

The study of animal exploration in the previous sub-section suggested that rewards associated with exploratory behavior are different from and independent of external rewards present in the environment. Thus, across species, there is an intrinsic motivation to explore novel environments (Gottlieb et al., 2013; Gottlieb \& Oudeyer, 2018; Liquin \& Lombrozo, 2020a, 2020b). What are the neural bases for this intrinsic motivation to explore? There is persistent evidence that the dopamine system, known to be at the basis of rewards across many species (e.g., Baumann et al., 2002; T. Hills, 2004; Schultz, 1998, 2015), reacts specifically to novel stimuli which do not involve any primary reward (Düzel et al., 2010; Horvitz et al., 1997; Kakade \& Dayan, 2002; Reed et al., 1996). Data from experiments with injections of a selective dopamine transporter inhibitor show that dopamine crucially enhances novelty-related value (Costa et al., 2014). A pivotal event-related fMRI study has shown that novel pictures activated the mid-brain Substantia Nigra and Ventral Tegmental Area (SN/TVA) more than rare, arousing and behaviorally relevant pictures (Bunzeck \& Düzel, 2006). That is, in the absence of reward, the dopamine system is activated by novel stimuli rather than interesting but more familiar ones. This supports the idea that "novelty can serve as its own reward" (Knutson \& Cooper, 2006) and more generally the novelty-based theory of exploration (Bromberg-Martin et al., 2010; Gottlieb \& Oudeyer, 2018; Kidd \& Hayden, 2015). The reaction of the dopamine system to novel stimuli has been interestingly referred to as "novelty bonuses" because it propels individuals towards potential future rewards through motor responses (Frank et al., 2009; Kakade \& Dayan, 2002; Koster et al., 2016; Krebs et al., 2009; Krueger et al., 2017; Sutton, 1990). A recent study combining computational modeling, fMRI and pharmacological intervention further suggested that the dopamine system reacts to uncertainty (Chakroun et al., 2020). Empirical results from fMRI studies also show that, while the neuronal system coding for novel informationseeking behavior recruits the dopamine-based reward system, non-explorative choices (i.e., exploiting existing information) recruit different brain regions (Blanchard \& Gershman, 2018; Chakroun et al., 2020; Costa et al., 2019; Daw et al., 2006). Exploration therefore accounts for a specific neuronal and cognitive domain (Blanchard \& Gershman, 2018).

\subsection{The variability of exploratory preferences: plastic responses to ecological cues}

Finally, we now go back to the ultimate level, to explain why and how exploratory preferences are flexible, and vary according to the local environment and the life stage of the individual (Baumard, 
2019; Frankenhuis et al., 2016; Jacquet et al., 2019; Nettle, 2019). The exploration-exploitation trade-off does depend on two main variables, time-horizon and risk aversion, determined by crucial ecological and individual factors.

\subsubsection{Exploratory preferences and risk}

Exploration, which encompasses risks, is sensitive to the level and steadiness of resources in the local environment, and more particularly to the observation of such ecological cues of harshness and unpredictability in early life (English et al., 2016; Humphreys et al., 2015). For instance, studies with rats showed that exploratory behavior decreases with early adversity in life (Spivey et al., 2008). The same results have been found in other species such as birds (Rojas-Ferrer et al., 2020) and bats (Carter et al., 2018). The same hypothesis has been held after having compared exploratory behavior between species in different ecological niches (Mettke-Hofmann et al., 2002) and between individuals from the same species in different ecological conditions. For instance, field observations suggest that wild orangutans avoid novelty and that juvenile acquire knowledge only through social learning. Conversely, zoo orangutans have been found to be a lot more curious and explorative, with the very same tests. This contrast is best explained by the ecological differences between the two environments: captive apes are fed and protected, and the costs of exploration such as resource shortage or predation risks are removed (Damerius et al., 2017; van Schaik et al., 2016).

Likewise, it is only in an affluent environment that humans should afford to invest more in unpredictable exploratory activities (Baumard, 2019). This is true at the level of the individual: individuals with a high and steady level of resources are more ready to invest in novel information through reward-approach behavior (Frankenhuis et al., 2016; Jacquet et al., 2019; Nettle, 2019). It is also true if we consider the evolution of humans: more affluent societies lead to better general standards of living and changes in individual cognitive preferences. For instance, this long-term psychological shift towards an "affluence mindset" is hypothesized to have contributed to the emergence of romantic love (Baumard et al., 2018), the industrial revolution (Baumard, 2019), scientific evolution (de Courson \& Baumard, 2019) and political revolutions (Martins \& Baumard, 2020; Safra et al., 2020). This slowly emerging mindset leads to more curious, long-term, innovative and creative thinking, making novel information more attractive to people. In other words, when surrounded by abundance, exploration is less risky and, thus, less costly.

\subsubsection{Exploratory preferences and time horizon}


The exploration-exploitation trade-off seems to depend on other variables such as age (Cohen et al., 2007; Stansfield \& Kirstein, 2006) and the species' life history strategy (Eliassen et al., 2007; Gopnik et al., 2020; Maspons et al., 2019; Sol et al., 2016). These results are best explained by hypothesizing that this trade-off is sensitive to time horizon, because it involves crucial opportunity costs such as waiting costs, i.e., the costs associated with delayed (as opposed to immediate) collection of resources (Boon-Falleur et al., 2020; Mell et al., 2019). Multiple optimal foraging models emphasize the discrepancy between the immediate costs of an exploratory strategy (e.g., the time allocated to the movements between patches, the decrease of the resource levels during search time) and the positive value of the acquired information for future exploitation (e.g., Eliassen et al., 2007; Maspons et al., 2019). In fact, exploration is best seen as a long-term investment in information, which is, as expected, more adaptive for individuals with less prior experience and higher expected life expectancy (Gopnik, 2020).

This is consistent with life-history strategies observed in multiple species: individuals go through an early period of exploration followed by a later period of exploitation (Morgan et al., 2020). This is particularly the case for human childhood which is longer than in any other species and allows for a long early protected period which can be devoted to both cognitive and spatial exploration, because major costs associated with exploration (e.g., resource shortage risk) are outweighed by parental caregiving investments (Gopnik et al., 2020; H. S. Kaplan et al., 2009). In developmental psychology, there is evidence that cues of social support such as maternal attentiveness and stimulation predict later exploratory behaviors in infants (Belsky et al., 1980; Rubenstein, 1967; SnellRood \& Snell-Rood, 2020). Finally, recent empirical studies show that human children and adolescents are better explorers and more motivated to explore than adults (Gopnik et al., 2015, 2017; Lucas et al., 2014).

\section{Exploratory preferences shape the content and form of fictions with imag- inary worlds}

Our hypothesis predicts that the attractive properties of real explorable environments should be heightened in fictions. The basic idea is that cultural items compete for the attention of audiences and, therefore, producers are likely to intensify appealing stimuli to increase the success of their works. For instance, Walt Disney's Mickey co-opts our visual preference for baby faces. It has been shown that the evolution of its design is driven by this preference: across the last decades, Mickey 
progressively became cuter, that is, more baby-like, with larger heads and more doting eyes (Gould, 2008; Hinde \& Barden, 1985). Likewise, because films have competed for the attention of moviegoers since the beginning of cinema, they have undergone continual changes. For example, over time, films have gotten faster (shot lengths have decreased) and darker (luminance have decreased), to better grab the attention of the viewers and improve their engagement in the film (Cutting et al., 2011). This 'superstimuli' hypothesis leads to four main predictions concerning imaginary worlds: across time, (1) information background should increase (2) imaginary worlds should get bigger, (3) protagonists should become more explorative and (4) imaginary worlds should always be renewed.

5.1. Fictions with imaginary worlds should generate more and more informational devices

\subsubsection{Theoretical background}

At the ultimate level, the function of exploration is to maximize the usefulness of knowledge, for potential future rewards. This means that any device enhancing the knowledge of the real world (e.g., navigation systems) should be attractive. If the appeal for imaginary worlds exploits the same exploratory preferences, fiction makers should target this evolutionary function by designing more and more apparently useful information devices leading to a better grasp of the imaginary world. They should also exaggerate such devices by making them even more useful as their real-world counterparts.

\subsubsection{Observations}

Fictions with imaginary worlds are very often accompanied with maps, paratexts and props (Saler, 2012). For instance, the rich map of Stevenson's Treasure Island, designed by his engineer father, is what drew people to this book (Wolf, 2013). Tolkien was the first fantasy author to include precise maps of an imaginary world. Since then, most fantasy fictions are released with maps of the imaginary locations. Some maps, such as Thror's map in The Hobbit and the Marauder's Map in Harry Potter, are actually used by the characters in the fictions. Likewise, open-world video games always include an interactive map which allow the players to find their way around the world. We also observe informational texts either included in the fictions (e.g., the Encyclopedia Galactica in Foundations) or published as books (e.g., Fantastic Beasts, a guidebook written by J.-K. Rowling on the magical creatures in the Wizarding World and Pandorapedia, James Cameron's encyclopedia of Avatar's imaginary world Pandora). Such guidebooks can even be written by other people who explain 
the imaginary worlds from their perspective (e.g., Philip Pullman's His Dark Materials: The Definitive Guide by Laurie Frost). Video games with open worlds have strategy guides which always include a complete map with the hard-to-find placement of all the items and detailed classifications of creatures, monsters, plants or locations, with their specific attributes. Finally, fandom wikis, that is, online encyclopedia with hierarchized information about imaginary worlds, are generated and updated by consumers.

\subsubsection{Predictions}

According to our exploration hypothesis, whatever makes the imaginary world easier to explore, be it maps, guidebooks, appendices, lists, footnotes or glossaries, should be an important factor of attraction. To our knowledge, there is currently no empirical or experimental evidence to support this claim. We predict that such informational devices about imaginary worlds are increasing in number with time, especially since the breakthrough of speculative genres, and that the fictions implementing them are on the whole associated with higher ratings (or any other indicators of cultural success). These are testable predictions further empirical research could focus on.

\subsection{Imaginary worlds should get bigger with time}

\subsubsection{Theoretical background}

We have reviewed findings showing that people rated images of environments higher when they could infer from the image that more information could be gained through exploration. A superstimulus of an environment is a world with more conspicuous opportunities to gain brand new information. A cue that an imaginary world is large thus functions as a crucial heuristic: in the absence of exploration-related costs, the bigger the environment, the more sources of reward can possibly be found. We thus predict that imaginary worlds get bigger with time.

\subsubsection{Observations}

It comes less as a surprise that the very first imaginary world comparable in size to the real world, Tolkien's world Arda, is extremely recent. Before 1914 (the first developments of Arda by Tolkien), humans had long begun to produce and consume literary fictions, and they didn't lack any cognitive abilities that would have prevented them to invent large imaginary worlds. However, only a few stories had developed large imaginary worlds (e.g., Dante's Hell) and virtually none had been 
precisely described and mapped. We hypothesize that the late appearance of large imaginary worlds is explained by (1) the slowness of the cultural evolution of imaginary worlds, which have gotten bigger and bigger, not at once, but over the long-term, and (2) by the ecological conditions of modern societies that recently made imaginary worlds more attractive (see section 6.3). Other recent examples make the case for such an explanation. In the science-fiction genre, the Galaxy from Asimov's fictional works (first developments in the early 1940') contain almost 25 million planets, with a dozen more precisely described. J.-K. Rowling's world is the first one to extend the real world with magical places hidden all around the planet. Both are very recent too. Since then, large and expandable environments seem to be the norm in speculative fictions: people expect very large and dense unfamiliar settings. We further predict that whether this expectation is met or not is a key determinant of their overall judgement of the fiction.

Video games, which is a recent fictional media, rapidly evolved to include big and open imaginary worlds, i.e., virtual worlds that the players can freely explore with "sandbox" gameplay (i.e., a gameplay that gives the player a great degree of freedom). With Grand Theft Auto III (2001), Assassin's Creed series (2007-2018), the Fallout series (1997-2018) and The Legend of Zelda: Breath of the Wild (2017), we observe an evolution towards bigger and bigger worlds, constrained by the advance of technology. Still, technological improvements could be used by video games in a lot of different manners and producers all chose to expand the world whenever possible. The example of No Man's Sky (2016) is compelling: through procedural generation of open worlds, it includes over 18 quintillion planets, with as many different imaginary environments which can be explored with complete autonomy from the players. Online multiplayer computer games with imaginary worlds have also been extremely popular over the last two decades. Dofus (2004), one of the first open imaginary world in an online game, now attracts 40 million players worldwide. World of Warcraft (2004), with its 100 million registered accounts, is one of the most popular massively multiplayer online roleplaying games (MMORPG) in the world. It is the fourth game to be set in the Warcraft world. Last but not least, Dungeon Fighter Online (2005) is the most played and highest grossing video game of all time, with 600 million players worldwide. These three highly successful online games are set in large and open imaginary worlds. More generally, in game design study, gamers are said to be "happiest with challenges that involve the gradual revelation of the world.” (Bartle, 2004).

Our prediction is supported by the observation of major marketing campaigns for successful fictions with imaginary worlds. Such campaigns aim at grabbing the attention of potential consumers and should therefore put all the attractive properties of the fiction to profit. We observe that 
marketing campaigns for such fictions often use the same heuristic: they show that a big world is going to be explored, by putting characters from behind embracing a large and open imaginary world (Figure 4). These images are very similar, in many ways, to the pictures used by scholars in environmental aesthetics for their questionnaire, categorized as "mysterious" landscapes, which were persistently better rated by the respondents.
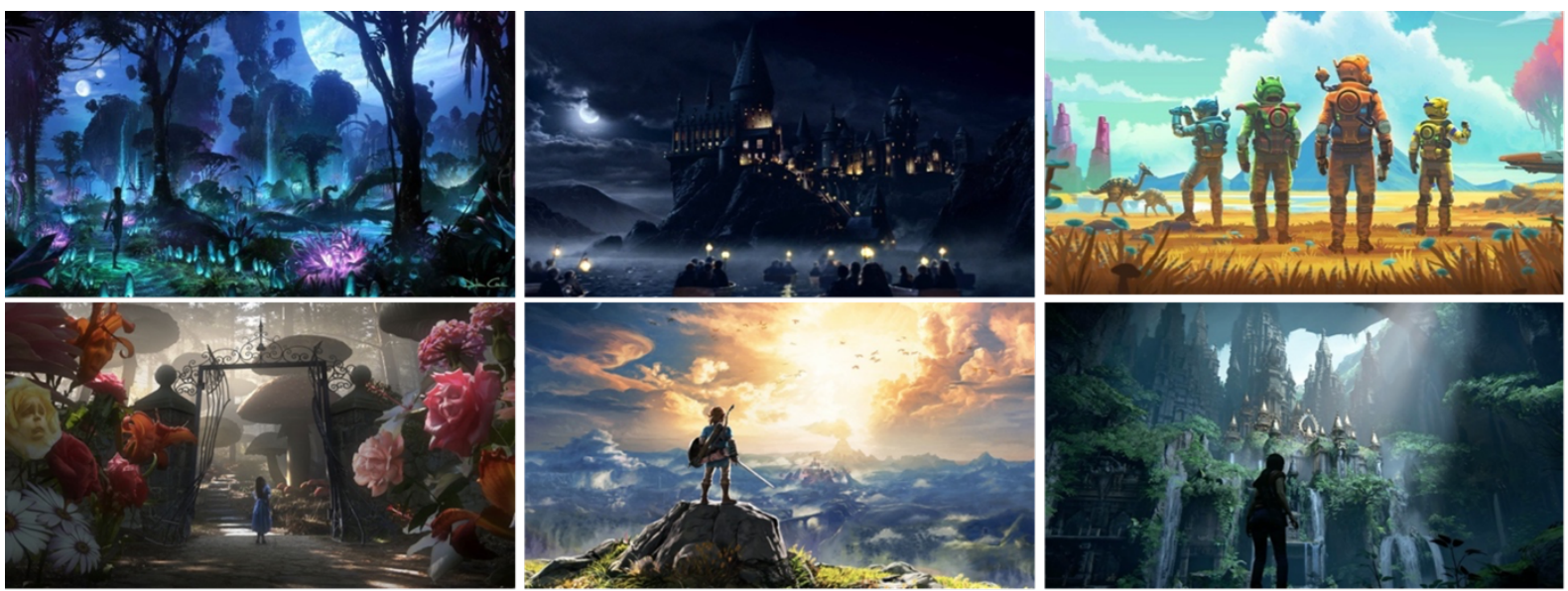

Figure 4. Images for the marketing campaigns of Avatar 2, Harry Potter and the Philosopher's Stone, No Man's Sky, Alice in Wonderland, The Legend of Zelda: Breath of the Wild and Uncharted.

\subsubsection{Predictions}

There is no empirical evidence to support this prediction yet. To test it, one could test experimentally whether gamers, for example, generally react positively to cues that the game world is going to be large. One could also craft a measuring tool to assess the size of imaginary worlds, with latent semantic analysis, a statistical linguistic method that can encode spatial structures stemming from big literary works (Louwerse \& Benesh, 2012). Such computational and text-based estimates of fictional environmental structures, if applied to enough written fictions, could assess whether such environments are increasing in size and structural complexity.

\subsection{Fictions with imaginary worlds should favor characters high in exploratory prefer- ences}

\subsubsection{Theoretical background}

From the claim that exploration is more adaptive in affluent local environments follows the hypothesis that, on the whole, exploratory preferences are more and more valued in modern societies. Therefore, according to our hypothesis, exploratory skills should be more and more prominent in 
fictions. Protagonists should be more and more explorative, just as they were generally strong and courageous in ancient stories. This is in line with the view according to which the protagonists' psychological traits are aligned with the preferred and expected psychological traits of ideal cooperative partners in a given place and time (Singh, 2019).

\subsubsection{Observations}

The first fictions with imaginary worlds were those in travel-based fictions, depicting epic heroes' journeys and travelers' adventures, such as The Odyssey (850 BCE) or Cervantes' Don Quixote (1612). In many contemporary fictions, characters still go and discover new lands. In The Chronicles of Narmia (Lewis, 1950), children are transported in an alternate realm; in His dark materials (Pullman, 1995), Lyra must travel into multiple alternate worlds; in Watership Down (Adams, 1972), rabbits must migrate far away from their warren to find a new home; and in Princess Mononoke (Miyazaki, 1997), Ashitaka must go where "no man has gone before" in order to cure a curse. In the Harry Potter novels, the many secret boundaries between the wizarding world and the common world are protected by the wizards, precisely because they live out of sight from the rest of the world. Harry, who knows nothing of this magical world before the age of 11, must explore a completely novel world from his perspective, and this is a task that is expanding over the seven books (Dubourg, 2020b).

In a great proportion of Disney films there is a world unfamiliar to some protagonists. The stories very often follow the same pattern. First, this world seems too far away or too dangerous to be explored. In the middle of the film, some adventurous protagonists end up crossing the symbolic border into the unknown world. In the Lion King (1994; the highest-grossing animated film and the second-highest-grossing film of all time), Simba, the young prince of the savanna, looks at his future kingdom and asks his father, the king: “-What about that shadowy place? — That's beyond our borders. You must never go there, Simba." Ten minutes later in the film, Simba convinces his young friend Nala to go and explore with him this novel environment. In Moana (2016), all the inhabitants of a small Polynesian island are forbidden by the chief to take the sea and explore what lies beyond the water. After a resource shortage, Moana, the chief's daughter, suggests going beyond the island's reef to find more fish. Although her parents still forbid it, she is drawn to the ocean by an exploratory instinct. Sher later finds out her ancestors were great explorers. She sings: “Every turn I take, every trail I track/ Is a choice I make, now I can't turn back/ From the great unknown where I go alone/ Where I long to be”. In Finding Nemo (the best-selling DVD title of all time), Marlin, an overprotective father, must cease to exploit his safe reef so as to go and explore 
the sea in search of his missing son. In $U p$ (winner of two Academy Awards), a 79-year-old man flies away to an unknown land in South America, with an accidental stowaway, a young Wilderness Explorer. In Alice in Wonderland, Alice decides to explore Wonderland. In Peter Pan, Wendy and his two brothers decide to explore the imaginary world of NeverLand. The list of films based on explorative characters who go to unknown locations goes on and on.

\subsubsection{Predictions}

There is to our knowledge no study analyzing the cultural evolution of fictional protagonists' psychological traits. To test this prediction, one could use the lexical tradition in personality psychology, which uses natural language trait adjectives to define and measure personality-related psychological constructs and apply the same methods on novels from various time periods. We predict that protagonists are more and more described as skillful explorers across history.

\subsection{Imaginary worlds should be different from each other}

\subsubsection{Theoretical background}

If imaginary worlds are culturally attractive and successful because of our exploratory preferences, then we should predict that to remain attractive and successful, imaginary worlds should constantly be renewed. That is, we predict that consumers are disappointed when two imaginary worlds resemble each other too much and that they actually condemn faithful imitations of previous imaginary worlds. This is the case because novelty is one key attractive component of imaginary worlds. This remark raises the question of why we are motivated to re-read or re-watch fictions with imaginary worlds. The most parsimonious explanation is that consumers exploit a reliable source of pleasure. However, we could also hypothesize that this is an extended exploratory strategy, that is, a way for the consumers to deepen their knowledge of the imaginary world. In fact, one of the interests of rereading, for instance, The Lord of the Ring is that one doing so gets to remember more names, more locations, and to better understand the imaginary world.

\subsubsection{Observations}

It is a mainstream observation: fictions with imaginary worlds are about innovative settings. In his book, Wolf rightly insists on the variety of the types of imaginary locations in fictions (Wolf, 2013): 
By the end of the nineteenth century, imaginary worlds had appeared all over the globe, underground, underwater, in outer space on the moon and other planets, in dreams, supernatural realms, other dimensions, in the distant past, the distant future, in alternate histories, and a few even existed independently of the Primary World.

Our exploration hypothesis more specifically predicts that producers should include various novel environments to keep the consumers excited about further adventures within the same fiction. For example, what is attractive in The Lord of the Ring is not only the size of the world, but also the variety of the types of locations within the world. The Shire is described as a peaceful and fertile land, with beautiful landscapes hosting forests (e.g., the Old Forest), rivers (e.g., River Brandywine) and bright green areas (e.g., Green Hill Country). Mordor, the realm of Sauron, is described as an evil land. The plateau of Gorgoroth, in the northwest, is depicted as arid, and it hosts the active volcano Mount Doom. Lithlad, in the east, is a dry plain. Likewise, the Star Wars galaxy is composed of various environments. Planets, to which characters travel by high-speed spaceships, are different from one another: Tatooine is a desert planet, Dagobah is a jungle planet, Hoth is an ice planet, etc. They all have distinct characteristics which are very well remembered by the fans. Finally, in the award-winning TV series Westworld, the Westworld is an amusement park designed to entertain people by putting them in a harsh and hostile environment, in which they must survive among often antagonistic man-like robots. In the second season, when viewers think they have learned everything there is to learn about the world in the first season, they discover that other amusement parks with different themes exist next to each other.

\subsubsection{Predictions}

Testing this prediction would imply to develop a tool to measure the innovativeness of imaginary worlds. For instance, we predict that the success of each type of imaginary location (e.g., a medieval fantasy world, a planet world, a magical world, a virtual world) decreases after its first development in a fiction. Because the behavior of consuming again a fiction with an imaginary world can be considered as an extended exploratory strategy, we also predict that everything being equal, people should be more tempted to re-read a story with an imaginary world than a story taking place in the real world, because we infer that in the former there is more new information that we might have missed.

Further research should also investigate if this intensification of innovation in the evolution of fictions with imaginary worlds has limits: not enough novelty could be disappointing or even boring, but, conversely, too much novelty could be bewildering, frustrating or too complex (Andersen 
et al., 2020; Clark, 2018; Kidd et al., 2012; Kiverstein et al., 2019). This question is to be asked for each stimulus intensification in cultural evolution. Following this view and our previous points, further research should engage questions such as: Can an imaginary world be too large? Can a protagonist be too curious and adventurous?

\section{Exploratory preferences explain the cultural distribution of imaginary worlds}

Our exploration hypothesis states that a bias for novel environment, which has evolved in a wide range of species to optimize knowledge acquisition and future rewards, is co-opted by fictions with imaginary worlds. From section 4.5, we inferred that not all people should develop exploratory preferences, because exploration is not adaptive in all ecological conditions. Our exploration hypothesis therefore states that the conditional factors we reviewed are determinant in the evoked cultural preferences for imaginary worlds. It would explain individual differences in the appeal for fictions with imaginary worlds. From this point, three main predictions follow: (1) fictions with imaginary worlds should be more attractive to people high in Openness to experience, (2) younger individuals should be more drawn to imaginary worlds than older individuals and (3) such imaginary worlds should captivate people surrounded by high and steady level of resources more than people in harsher local environments.

6.1 Imaginary world should be more attractive to people high in Openness to experience

\subsubsection{Theoretical background}

If imaginary worlds co-opt our exploratory preferences, the appeal for imaginary worlds should be associated with the psychological trait Openness to experience and more generally with the motivation to gather knowledge about the real environment.

\subsubsection{Observations}

This prediction is consistent with the observation that consumers of fictions with imaginary worlds are highly educated. For instance, $82,4 \%$ of the survey with science fiction and fantasy fans report being educated to university level or above (Menadue \& Jacups, 2018). This compares to $46 \%$ of the United States population, $50 \%$ of Australians, and $46 \%$ of the United Kingdom population 
(Organization for Economic Co-Operation and Development, 2017). This reinforces previous audience data that found "astonishing" high levels of education among the science fiction readership (Berger, 1977, p. 236). The above-average reading volume reported in the same survey may be related to the high levels of educational attainment of the sample population.

In a recent paper, Nave et al. (2020) studied the association between the Big 5 personality traits and a range of cinematographic genres in Facebook users ( $N=3,5$ million). In line with our hypothesis, they show a strong association between Openness to experience and a preference for fantasy and science-fiction movies (meaning that speculative fictions tend to be liked by people high on Openness to experience). Using the same dataset (Dubourg, Thouzeau, et al., 2021), we show that the association with Openness to experience is even higher for films with imaginary worlds than for speculative fictions. It is worth noting that, by contrast, fictions with imaginary worlds are associated with lower level of Extraversion, Conscientiousness, Agreeableness and Neuroticism.

\subsubsection{Predictions}

We further hypothesize the existence of "fictional syndromes" that is, clusters of preferences associated with preferences for some fictional genres, that co-occur because they tap into the same cognitive mechanisms. We predict that individuals with higher level of exploratory preferences preferably read fictions with imaginary worlds as well as other world-dominant fictions (e.g., historical novels, social realistic novels) and non-fiction works dense in information.

Research in personality traits has found that people high in Openness to experience are more likely to be tolerant of diversity, liberal, opened to new lifestyles and opposed to right-wing political orientations (Butler, 2000; Sibley \& Duckitt, 2008). We thus predict that fans of such fictions are more politically tolerant and socially liberal. This is consistent with the recent observation that fans of speculative fictions are more politically progressive and committed against prejudice (Besson, 2021). This reasoning predicts that people who enjoy imaginary worlds should also enjoy fictions exploring new social roles (Mar, 2018; Mar \& Oatley, 2008).

6.2. Imaginary worlds should be more attractive to children, teenagers and young adults

\subsubsection{Theoretical background}


We have reviewed research in various fields showing why children have higher preferences for exploration than adults. First, the time-horizon variable, which is a key determinant of the exploration-exploitation trade-off, makes exploration more adaptive for children whose expected life expectancy is higher. Second, major costs associated with exploration are outweighed by parental investments. This is why children can afford to be more motivated to explore novel environments. Our exploration hypothesis thus predicts that children should be more attracted to fictions with imaginary worlds.

\subsubsection{Observations}

First, we commonly observe that humans develop an early interest for imaginary worlds. Scholars in the field of developmental psychology called the imaginary worlds created by children in their mind, as part of make-believe play, "paracosms" (Harris, 2000; Root-Bernstein, 2013, 2014; RootBernstein \& Root-Bernstein, 2006; Silvey \& MacKeith, 1988; Taylor et al., 2020). This body of work is particularly relevant insofar as the activity involves the creation of invented locations with real props, such as drawings, maps and artifacts made by the children engaging with their internal worldplays (Root-Bernstein, 2013). Such props are much like the objects we find associated with recent imaginary worlds. Let's think, for instance, of the map of Tolkien's world of Arda and of the movie merchandises (i.e., replications of fictional artefacts), such as Harry Potter wands or the alethiometer from Philip Pullman's His Dark Materials. Empirical works on paracosms found that a substantial number of children engage in such worldbuilding activities (e.g., Taylor et al., 2020). Children are not fooled by fictions: just like adults, they can intuitively make the distinction between reality and fiction (Dubourg, 2020a), and between fictional worlds (Skolnick \& Bloom, 2006).

Besides, consumers of fictions with imaginary worlds are typically young (Besson, 2015). For example, young readers are targeted by massively consumed novels in the fantasy genre, sometimes adapted for the screen with unparalleled successes. Let's think, for instance, of Tolkien's The Hobbit (1937), Horowitz's Groosham Grange (1988), Riordan's Percy Jackson (2005-2009), Rowling's Harry Potter (1997-2007), Pullman's His Dark Materials (1995-2000), Saint-Exupéry's The Little Prince (1943) and Colin's Hunger Games (2008-2020). All these highly successful books are edited in the children's collections from the publishing houses. In a socio-economic study about science-fiction fans, with 282 questionnaires, more than $80 \%$ of the respondents said they began to read science fiction before the age of 15 (Berger, 1977). In another study on the correlation between literary taste patterns and social differentiation in Finland, age was the only variable which significatively decreased the liking of speculative fictions, whereas age had no such effect on other fictional genres 
(Purhonen et al., 2009). Finally, in Dubourg, Thouzeau et al. (2021), we found a significative association between age and a preference for movies with imaginary worlds: such movies tend to be liked by younger people.

\subsubsection{Predictions}

We further predict that, as societies become more affluent, people grow out of the fondness for imaginary worlds at a later and later age, because in such local environments they should afford to remain explorative longer. This would explain why a new target audience has recently emerged, the one of young adult, with associated editorial collections very often specialized in speculative genres (i.e., YA literature). To our knowledge, our approach is the only one which consistently explains the correlation between the cultural preference for imaginary worlds and the age of consumers.

\subsection{Imaginary worlds should be more attractive to people living in affluent environments}

\subsubsection{Theoretical background}

We have shown that exploration is more adaptive in a predictable and affluent ecology, because of the risk variable involved in the exploration-exploitation trade-off: if the level of resources in the local environment is high and steady enough, individuals can afford to be more explorative and phenotypic plasticity can thus promote a future-oriented mindset. In rich local environments, individuals become more motivated to explore both the real world and imaginary worlds. Our exploration hypothesis therefore predicts that, both at the level of the individual and at the level of societies, affluency is a predictor of the attractiveness of imaginary worlds.

\subsubsection{Observations}

A recent empirical survey $(\mathrm{N}=909)$ provided insights about the socio-economic status of science fiction and fantasy fans (Menadue \& Jacups, 2018). To the question about income satisfaction level, most respondents answered: "I do well enough" (54,1\%), and 32\% answered "I'm happy with what I have" or "I have more than I need". Such readers also have curious and open-minded psychological traits. For instance, 95,2\% reported they found new and unfamiliar ideas easy to understand. Because this study is based on a selected sample, we lack data to compare these results with the socio-economic status and personality traits of readers of other fictional genres, but it still confirms that consumers of speculative fictions fit the prediction made by our exploration hypothesis. In 
another study, in Finland, speculative fictions were found to be significatively more read by people with higher income, whereas income as a variable had no effect on the consumption of other genres (Purhonen et al., 2009).

At the global level, our hypothesis predicts that imaginary worlds should be more popular in economically more developed country. In line with this idea, modern imaginary worlds emerged in the United Kingdom (Wolf, 2013), which was at the time the leading country in term of GDP per capita (Manning, 2017), and then mostly developed in the Euro-American sphere. For instance, while Jules Verne was first translated in Chinese in the early 20th and inspired Chinese writers to write science-fiction and fantasy stories during the late Qing dynasty and early Republican era, fictions based on imaginary worlds remained marginal in Chinese literature during the 20th century (Jiang, 2013). Imaginary worlds started to become popular first in Hong-Kong and Taiwan, which started to develop in the 1970 and really became mainstream in mainland China in the turn of the new millennium, that is, 20 years after the take-off of the Chinese economy (Song, 2013).

In a recent work (Dubourg, Thouzeau, et al., 2021), we studied the evolution of the share of fictions with imaginary worlds in 11 countries, since the beginning of the $19^{\text {th }}$ century, with data extracted from Wikidata $(\mathrm{N}=44,608)$. We find trends indicating that, in most countries, when GDP per capita increases, the share of speculative fictions rises too. We fit a Linear Mixed-Effect Model to the data, with countries as random factor, and we find a positive and significant association between GDP and the share of speculative novels $(B=0.048218, \mathrm{p}=6.91 \mathrm{e}-09$; Figure 5).

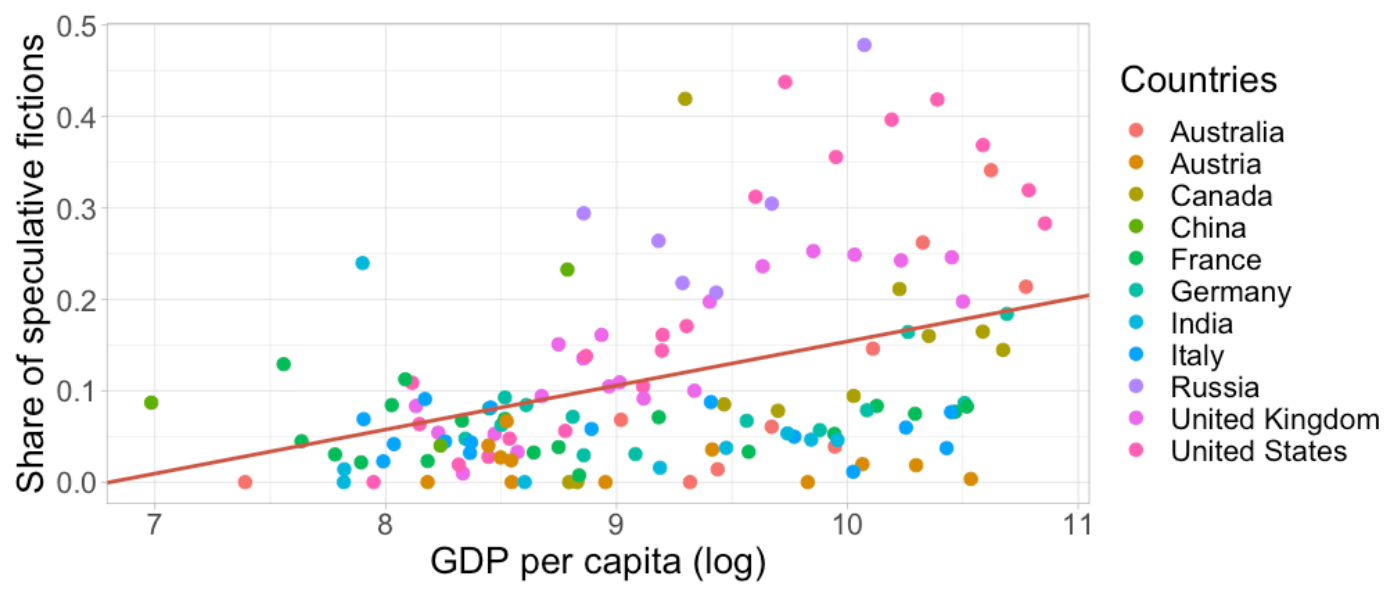

Figure 5. The share of speculative novels (as a proxy for the success of novels with imaginary worlds) as a function of the log of GDP per capita in 11 countries, with a regression line of the Linear Mixed Effect Model. 
We also studied the evolution of the share of speculative fiction in the United States $(\mathrm{N}=27,432)$. We used speculative genres as a proxy for imaginary worlds. We found a strong correlation between GDP per capita and the share of speculative fiction ( $\beta=0.15747^{* * *}, \mathrm{p}<2 \mathrm{e}-16$, adjusted $\mathrm{R}^{2}=0.6714$ ). This result is consistent with the idea that speculative fictions and more specifically fictions with imaginary worlds tend to be more attractive in more developed countries (Figure 6).

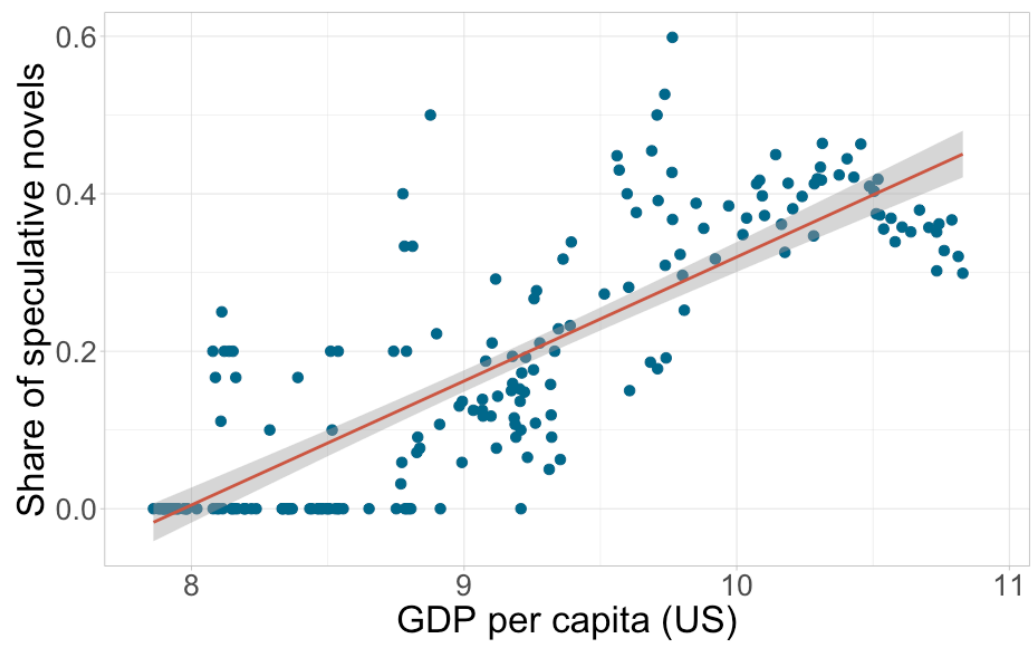

Figure 6. The share of American speculative novels (as a proxy for the success of novels with imaginary worlds) as a function of the GDP per capita in the United States, with the regression line of the Linear Model.

We also studied another indicator of success, namely the box-office of films based on imaginary worlds in the United States (Dubourg, Thouzeau, et al., 2021). An indicator of the success of films with imaginary worlds (IWS indicator) was computed by subtracting, for a given year, the mean box-office of films with imaginary worlds and the mean box-office of films with no imaginary worlds, in the United States. The value and the sign of this indicator tells us about the relative success of films with imaginary worlds. This indicator is highly and positively correlated to the GDP per capita in the United States $\left(\beta=8.022 \mathrm{e}-05^{* * *}, \mathrm{p}=0.2 .09 \mathrm{e}-08\right.$, adjusted $\mathrm{R}^{2}=0.3715$; Figure 7). 


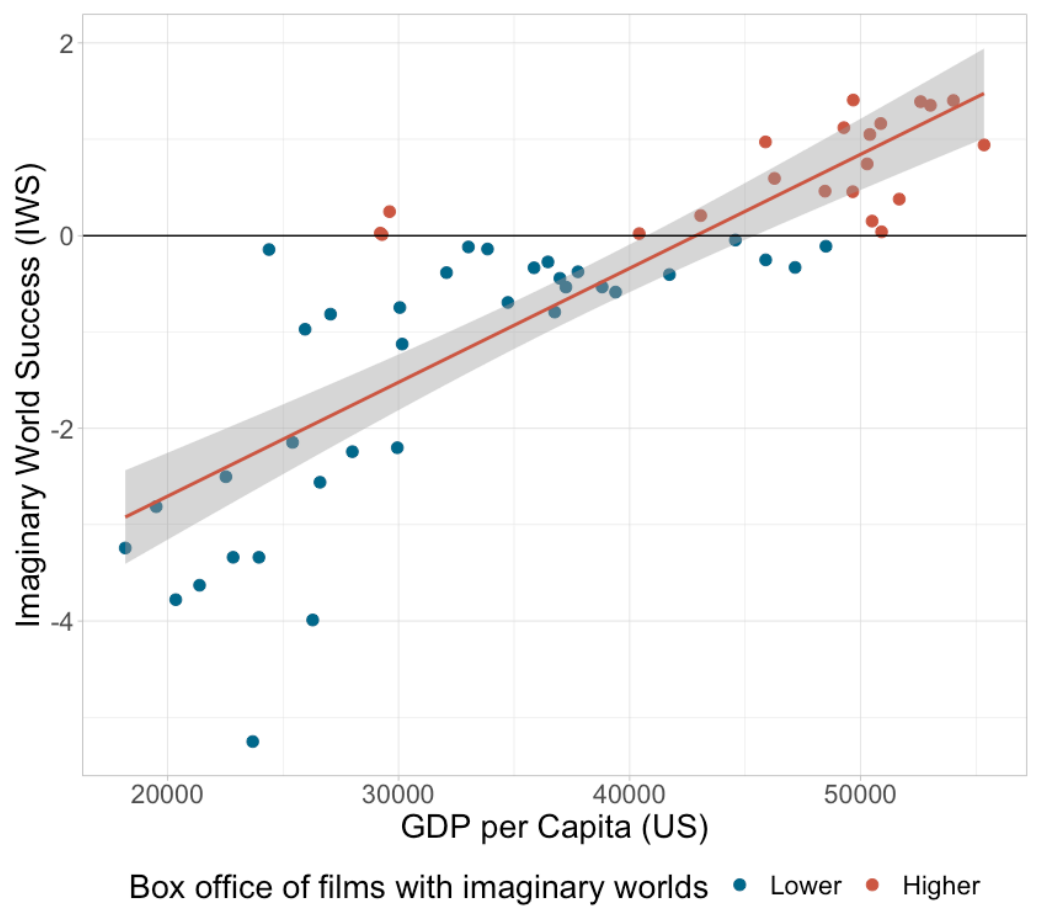

Figure 7. The success of films with imaginary worlds (IWS) as a function of the GDP per capita in the United States, with the regression line of the Linear Model and a vertical line at $y=0$ (above which the mean box office of films with imaginary worlds becomes bigger than the mean box office of films with no imaginary world).

\subsubsection{Predictions}

It would be interesting to test whether the quantitative analysis of the success of fictions with imaginary worlds and its association with affluence indicators replicate in non-Western developed countries (e.g., Japan, Korea) and in non-Western developing countries (e.g., India, Nigeria).

\section{Discussion}

\subsection{Remaining questions about imaginary worlds}

In research fields interested in fictions, there has long been a focus on "who" and "how" questions, about plots and protagonists, at the expense of "where" questions, about settings, probably because of our narrative-oriented understanding of fictions. As Ryan recently wrote, "narrative space remains a relatively unexplored territory" (Ryan, 2014). In this article, we have provided evidence that narrative spaces, and in particular imaginary worlds, are central in modern fictions partly because they tap into human's preferences for exploration, which have been co-opted by cultural evolution for entertainment. This hypothesis led to several fine-grained predictions about the cultural evolution of imaginary worlds. These predictions were supported by empirical research, 
whenever available. Obviously, more research is needed to further test this theory. For instance, we need to be able to quantify the size and diversity of imaginary worlds, as well as the amount of background information associated with a particular world. The existence of literary syndromes should also be tested rigorously. Besides, many questions remain unsolved: what exactly is the cultural advantage of fiction with imaginary worlds over non-fictions describing the real world (history books and travel books)? Why are medieval fantasy and space opera so attractive? Is there an ideal cognitive trade-off between too much imagination and too much similarity with the real world? The latter question has been addressed for social networks in fictions, which are constrained by our cognitive mechanisms (Dunbar, 2017; Gessey-Jones et al., 2020) but, to our knowledge, no empirical research has tested the limits of the processing of novelty in human culture.

\subsection{Alternative and compatible explanations}

On another note, other sets of cognitive mechanisms might play an important role in the appeal for imaginary worlds, and we do not rule out other complementary explanations. For example, systemizing seems central in the appreciation of world-dominant fictions, be it imaginary (e.g., Star Wars) or not (e.g., Sherlock Holmes). At the proximate level, humans are lured by new environments, but there is much evidence that they also prefer rich and organized ones (S. Kaplan, 1987), and this might come from our drive to systemize (Baron-Cohen, 2002) and from our cognitive mechanisms which make us intuitively think about plants and animals in highly structured ways (Atran, 1998). This hypothesis is consistent with recent cognitive frameworks stating that curiosity seeks both novelty and complexity to maximize knowledge acquisition (Brändle et al., 2020; Dubey \& Griffiths, 2020), and it better echoes the "encyclopedic impulse" scholars in cultural and literary studies targeted to explain the attractiveness of world-dominant fictions that grab the attention of people interested in accumulating and organizing knowledge (Besson, 2015; Eco, 1997; Wolf, 2013). It leads to testable predictions about sex differences in cultural preferences for highly structured imaginary worlds. Large imaginary worlds seem also to lead to denser narrative displays. The human mind has evolved a relevancy detector system (Sperber \& Wilson, 1987) which is highly exploited by fictions (D. Wilson, 2018). It seems especially true for contemporary world-dominant fictions which expand over various works, in different media (e.g., the Marvel Cinematic Universe). Each new information impacts plenty other related fictions. It seems we expect all pieces of information to fit and be consistent with each other. This is notably evidenced by the fans' vivid reactions to any inconsistency, especially for fictions with imaginary worlds that contain a lot of background information (Besson, 2015). Future research on popular fictions with imaginary worlds could focus on such complementary dimensions. 


\subsection{Exploratory preferences and other cultural trends}

Our hypothesis could also explain other trends in the cultural evolution of fictions. For instance, fanfictions (i.e., fictional writings written by fans and based on previous canonical fictional works) have become highly mainstream in many countries (e.g., döjinshi in Japan, Star Trek fanzine in the United States) and are beginning to be taken very seriously by consumers and the publishing industry. Gamers too started to computationally create more content for their favorite video games, with the intention of sharing it with others. Such alterations of the games are called "mods" (short for "modifications"). More and more game studios create mod tools to ease this process. This massive cultural phenomenon, with fans reshaping and improving video games for the sole benefit of the mod community, and free of charge, has been overlooked in psychological and cognitive research fields (Poor, 2014; Sotamaa, 2010). It has never been put in parallel with literary fan fictions nor with the literature on exploration and curiosity. More generally, the motivation behind unpaid user-generated content (UGC) has mainly been explained with social benefits (Chavez et al., 2020; Crowston \& Fagnot, 2018; Daugherty et al., 2008; Omar \& Dequan, 2020; Sun et al., 2017) and economic incentives (Poch \& Martin, 2015). We argue that our exploration hypothesis could better explain this drive to create new cultural content without any direct return on investment. It relates to the examples we mentioned of many animals that seeks novelty even in presence of other primary rewards, and even with experimentally added costs. Humans seek so much for new information that it may well push fans to create new content, even at some costs. In other words, according to our hypothesis, modders, writers of fan fictions and other participants of UGC are best seen as curious explorers.

Our hypothesis could also contribute to clarify the cognitive bases of other types of fiction, such as interactive books, films and TV series (e.g., Black Mirror: Bandersnatch, 2018), or, to a lesser extent, crime, mystery, horror and detective fictions. These genres arguably tap into our exploratory preferences, but not into spatial exploration per se. Rather, they seem to exploit an uncertainty-based form of exploration. We therefore believe fictions in these genres target the related mechanisms designed to minimize uncertainty and seek for reason-based explanations (Gottlieb et al., 2013; Grodal, 2010; Liquin \& Lombrozo, 2020a). In other words, fictions in such genres are often storydominant fictions co-opting our exploratory preferences with surprising plot outcomes. Even story-dominant fictions could exploit our exploratory preferences, through the exploration of unknown social roles (Abbott, 2013), a kind of exploration which relies on our social simulation abilities (Hasson et al., 2012; Mar et al., 2006; Mar \& Oatley, 2008). Finally, our exploratory 
preferences are also co-opted by other cultural products. For instance, in Sub Terra, a popular and awarded boardgame, the players' goal is to explore a map which is revealed progressively.

\subsection{The cognitive and evolutionary study of fiction}

We now discuss some broader conclusions our paper brings about. First, our paper adds further support to the cultural attraction theory according to which human culture is influenced by our cognitive biases (Boyer, 2018; Claidière et al., 2014; Claidière \& Sperber, 2007; Morin, 2016; ScottPhillips et al., 2018; Singh, 2019). Culture is neither faithfully nor randomly transmitted, but rather reconstructed in a way shaped by our cognition. The cultural evolution of imaginary worlds is one example of this cultural evolutionary process: a set of cognitive mechanisms which evolved to solve the adaptive trade-off between exploration and exploitation drives the evolution of fictions with imaginary worlds. Following this view, we disentangled two main paths through which imaginary worlds culturally evolved: imaginary worlds have changed over the course of history (1) because our exploratory preferences evolved to adapt to crucial ecological changes, through phenotypic plasticity, and (2) because producers of fictions target and exaggerate already preferred stimuli.

Second, we expect that our findings could be relevant for literary theory, cultural history and fiction study. For instance, the existence of distinct genres such as horror, comedy and detective fictions has been said to derive from the involvement of distinct sets of cognitive mechanisms (Clasen, 2010; Clasen et al., 2018; Clasen \& Platts, 2019; Fishelov, 1995; Grodal, 2010, 2017). Our work extends this on-going research program and could also support the cognitive studies of fictional media, such as cinema (Jullier, 2018; Tan, 2018). We believe our exploration hypothesis, if supported by more empirical evidence, can also be used by scholars in evolutionary psychology and computational history. The consumption of fictions with imaginary worlds could be used as a behavioral proxy to measure the evolution of exploratory preferences, offering insights on their adaptive flexibility to the changing environments.

\subsection{Broader implications of the exploration hypothesis}

Finally, it is our belief that this paper could be relevant outside the research domain too, for education and fiction production. The fact that children are intrinsically captivated by imaginary worlds suggests that such fictions should be brought into the classrooms. The links between curiosity and learning being increasingly understood (Gordon et al., 2015; Wade \& Kidd, 2019), cultural attraction theory could be a relevant and useful framework to design curiosity-based learning 
interventions. More generally, exploring which types of fictions exploit which cognitive mechanisms brings about new predictions about the socio-psychological determinants of the attractiveness of specific cultural items. Further research in this domain could lead to more fine-grained and evidence-based individual suggestions of which fictions to read or watch. This would have direct implications for the fiction industry and their recommendation algorithms (Nave et al., 2020).

Acknowledgment: Mélusine Boon-Falleur, Valerian Chambon, Charles de Dampierre, Léo Fitouchi, Hugo Mercier, Olivier Morin and Valentin Thouzeau.

Funding statement: This work was supported by the FrontCog funding (ANR-17-EURE-0017). Conflicts of Interest: None.

\section{ORCID}

Edgar Dubourg: 0000-0002-2162-6526

\section{References}

Abbott, H. P. (2013). Real mysteries: Narrative and the unknowable. Ohio State University Press. Alberti, J. (2013). "I Love You, Man": Bromances, the Construction of Masculinity, and the Continuing Evolution of the Romantic Comedy. Quarterly Review of Film and Video, 30(2), 159-172. https://doi.org/10.1080/10509208.2011.575658

Alves, I., Arenas, M., Currat, M., Sramkova Hanulova, A., Sousa, V. C., Ray, N., \& Excoffier, L. (2016). Long-Distance Dispersal Shaped Patterns of Human Genetic Diversity in Eurasia. Molecular Biology and Evolution, 33(4), 946-958. https://doi.org/10.1093/molbev/msv332

Andersen, M. M., Schjoedt, U., Price, H., Rosas, F. E., Scrivner, C., \& Clasen, M. (2020). Playing With Fear: A Field Study in Recreational Horror. Psychological Science, 095679762097211. https://doi.org/10.1177/0956797620972116

André, J.-B., \& Baumard, N. (2020). Cultural evolution by capital accumulation. Evolutionary Human Sciences, 2, e18. https://doi.org/10.1017/ehs.2020.19

André, J.-B., Baumard, N., \& Boyer, P. (2020). The Mystery of Symbolic Culture: What fitness costs? What fitness benefits? 18. https://osf.io/kdh7t/download?format=pdf

Atran, S. (1998). Folk biology and the anthropology of science: Cognitive universals and cultural particulars. Behavioral and Brain Sciences, 21(4), 547-569. https://doi.org/10.1017/S0140525X98001277

Bakhtin, M. M., \& Emerson, C. (1984). Problems of Dostoevsky's poetics. University of Minnesota Press.

Balling, J. D., \& Falk, J. H. (1982). Development of Visual Preference for Natural Environments. Environment and Behavior, 14(1), 5-28. https://doi.org/10.1177/0013916582141001

Baron-Cohen, S. (2002). The extreme male brain theory of autism. Trends in Cognitive Sciences, 6(6), 248-254. https://doi.org/10.1016/S1364-6613(02)01904-6 
Bartle, R. A. (2004). Designing virtual worlds. New Riders Pub.

Baumann, O., Dames, P., Kühnel, D., \& Walz, B. (2002). Distribution of serotonergic and dopaminergic nerve fibers in the salivary gland complex of the cockroach Periplaneta americana. BMC Physiology, 15.

Baumard, N. (2019). Psychological origins of the Industrial Revolution. Behavioral and Brain Sciences, 42, e189. https://doi.org/10.1017/S0140525X1800211X

Baumard, N., Huillery, E., \& Zabrocki, L. (2018). The Origins of Romantic Love and Asceticism: How Economic. 42.

Behrens, T. E. J. (2018). What Is a Cognitive Map? Organizing Knowledge for Flexible Behavior. 20.

Belsky, J., Goode, M. K., \& Most, R. K. (1980). Maternal Stimulation and Infant Exploratory Competence: Cross-Sectional, Correlational, and Experimental Analyses. Child Development, 51(4), 1168. https://doi.org/10.2307/1129558

Berger, A. I. (1977). Science-Fiction Fans in Socio-Economic Perspective: Factors in the Social Consciousness of a Genre. Science Fiction Studies, 4(3,), 232-246.

Berlyne, D. E. (1950). NOVELTY AND CURIOSITY AS DETERMINANTS OF EXPLORATORY BEHAVIOUR1. British Journal of Psychology. General Section, 41(1-2), 68-80. https://doi.org/10.1111/j.2044-8295.1950.tb00262.x

Berlyne, D. E. (1970). Novelty, complexity, and hedonic value. Perception \& Psychophysics, 8(5), 279-286. https://doi.org/10.3758/BF03212593

Besson, A. (2015). Constellations: Des mondes fictionnels dans l'imaginaire contemporain. CNRS éditions.

Besson, A. (2021). Les pouvoirs de l'enchantement: Usages politiques de la fantasy et de la science-fiction.

Blanchard, T. C., \& Gershman, S. J. (2018). Pure correlates of exploration and exploitation in the human brain. Cognitive, Affective, \& Behavioral Neuroscience, 18(1), 117-126. https://doi.org/10.3758/s13415-017-0556-2

Block, A. B., \& Wilson, L. A. (Eds.). (2010). George Lucas's blockbusting: A decade-by-decade survey of timeless movies, including untold secrets of their financial and cultural success (1st ed). itBooks.

Bloom, P. (2010). How pleasure works: The new science of why we like what we like (1st ed). W. W. Norton.

Boon-Falleur, M., Baumard, N., \& André, J.-B. (2020). Risk-seeking or impatient? Disentangling variance and time in hazardous behaviors [Preprint]. PsyArXiv. https://doi.org/10.31234/osf.io/phtm8

Borel, A., Ajzenherc, Y., Moncel, M.-H., Saint Jalme, M., \& Krief, S. (2016). Do Orangutans Share Early Human Interest in Odd Objects? Current Anthropology, 57(6), 828-837. https:// doi.org/10.1086/688855

Bourdieu, P. (1979). La distinction: Critique sociale du jugement. Éditions de Minuit.

Bown, N. J., Read, D., \& Summers, B. (2003). The lure of choice. Journal of Behavioral Decision Making, 16(4), 297-308. https://doi.org/10.1002/bdm.447

Boyd, B. (2018). The evolution of stories: From mimesis to language, from fact to fiction: The evolution of stories. Wiley Interdisciplinary Reviews: Cognitive Science, 9(1), e1444. https://doi.org/10.1002/wcs.1444

Boyer, P. (2001). Religion explained: The evolutionary origins of religious thought. Basic Books.

Boyer, P. (2018). Minds make societies: How cognition explains the world humans create. Yale University Press.

Brändle, F., Wu, C. M., \& Schulz, E. (2020). What are we curious about? [Preprint]. PsyArXiv. https://doi.org/10.31234/osf.io/y2835 
Broglio, C., Rodríguez, F., \& Salas, C. (2003). Spatial cognition and its neural basis in teleost fishes. Fish and Fisheries. https://doi.org/10.1046/j.1467-2979.2003.00128.x

Bromberg-Martin, E. S., Matsumoto, M., \& Hikosaka, O. (2010). Dopamine in Motivational Control: Rewarding, Aversive, and Alerting. Neuron, 68(5), 815-834. https://doi.org/10.1016/j.neuron.2010.11.022

Bunzeck, N., \& Düzel, E. (2006). Absolute Coding of Stimulus Novelty in the Human Substantia Nigra/VTA. Neuron, 51(3), 369-379. https://doi.org/10.1016/j.neuron.2006.06.021

Buss, D. M. (2015). Evolutionary psychology: The new science of the mind (Fifth edition). Pearson.

Butler, J. C. (2000). PERSONALITY AND EMOTIONAL CORRELATES OF RIGHTWING AUTHORITARIANISM. Social Behavior and Personality: An International Journal, 28(1), 1-14. https://doi.org/10.2224/sbp.2000.28.1.1

Byrne, R. W. (2013). Animal curiosity. Current Biology, 23(11), R469-R470. https://doi.org/10.1016/j.cub.2013.02.058

Canet, F. (2016). Quantitative approaches for evaluating the influence of films using the IMDb database. Communication \& Society, 29(2), 151-172. https://doi.org/10.15581/003.29.2.151-172

Carbone, E., Meneghetti, C., \& Borella, E. (2019). The influence of personality traits and facets on visuo-spatial task performance and self-assessed visuo-spatial inclinations in young and older adults. PLOS ONE, 14(8), e0220525. https://doi.org/10.1371/journal.pone.0220525

Carbone, E., Meneghetti, C., \& Borella, E. (2020). The role of personality in route learning in young and older adults. Personality and Individual Differences, 166, 110187. https://doi.org/10.1016/j.paid.2020.110187

Carroll, J. (2012). Literary Darwinism: Evolution, human nature, and literature. Routledge. https://www.taylorfrancis.com/books/e/9780203505274

Carter, G. G., Forss, S., Page, R. A., \& Ratcliffe, J. M. (2018). Younger vampire bats (Desmodus rotundus) are more likely than adults to explore novel objects. PLOS ONE, 13(5), e0196889. https://doi.org/10.1371/journal.pone.0196889

Cashdan, E., \& Gaulin, S. J. C. (2016). Why Go There? Evolution of Mobility and Spatial Cognition in Women and Men: An Introduction to the Special Issue. Human Nature, 27(1), $1-$ 15. https://doi.org/10.1007/s12110-015-9253-4

Catania, A. C. (1980). Freedom of Choice: A Behavioral Analysis. In Psychology of Learning and Motivation (Vol. 14, pp. 97-145). Elsevier. https://doi.org/10.1016/S0079-7421(08)60160-7

Catania, A. C., \& Sagvolden, T. (1980). PREFERENCE FOR FREE CHOICE OVER FORCED CHOICE IN PIGEONS. Journal of the Experimental Analysis of Behavior, 34(1), 77-86. https://doi.org/10.1901/jeab.1980.34-77

Chakroun, K., Mathar, D., Wiehler, A., Ganzer, F., \& Peters, J. (2020). Dopaminergic modulation of the exploration/exploitation trade-off in human decision-making. ELife, 9, e51260. https://doi.org/10.7554/eLife.51260

Chambon, V., Thero, H., Findling, C., \& Koechlin, E. (2018). Believing in one's power: A counterfactual heuristic for goal-directed control [Preprint]. Neuroscience. https://doi.org/10.1101/498675

Chapman, B. B., Hulthén, K., Wellenreuther, M., Hansson, L.-A., Nilsson, J.-Å., \& Brönmark, C. (2014). Patterns of animal migration. In L.-A. Hansson \& S. Åkesson (Eds.), Animal Movement Across Scales (pp. 11-35). Oxford University Press. 
https://doi.org/10.1093/acprof:oso/9780199677184.003.0002

Chavez, L., Ruiz, C., Curras, R., \& Hernandez, B. (2020). The Role of Travel Motivations and Social Media Use in Consumer Interactive Behaviour: A Uses and Gratifications Perspective. Sustainability, 12(21), 8789. https://doi.org/10.3390/su12218789

Claidière, N., Scott-Phillips, T. C., \& Sperber, D. (2014). How Darwinian is cultural evolution? Philosophical Transactions of the Royal Society B: Biological Sciences, 369(1642), 20130368. https://doi.org/10.1098/rstb.2013.0368

Claidière, N., \& Sperber, D. (2007). The role of attraction in cultural evolution. Journal of Cognition and Culture, 7(1-2), 89-111. https://doi.org/10.1163/156853707X171829

Clark, A. (2018). A nice surprise? Predictive processing and the active pursuit of novelty. Phenomenology and the Cognitive Sciences, 17(3), 521-534. https://doi.org/10.1007/s11097-017$9525-z$

Clasen, M. (2010). The Horror! The Horror! The Evolutionary Review, 1, 112-119.

Clasen, M., Kjeldgaard-Christiansen, J., \& Johnson, J. A. (2018). Horror, personality, and threat simulation: A survey on the psychology of scary media. Evolutionary Behavioral Sciences. https://doi.org/10.1037/ebs0000152

Clasen, M., \& Platts, T. K. (2019). Evolution and Slasher Films. In D. Vanderbeke \& B. Cooke (Eds.), Evolution and Popular Narrative. Brill | Rodopi. https://doi.org/10.1163/9789004391161_003

Clay, D. (2007). The Islands of the Odyssey. Journal of Medieval and Early Modern Studies, 37(1), 141-161. https://doi.org/10.1215/10829636-2006-013

Cohen, J. D., McClure, S. M., \& Yu, A. J. (2007). Should I stay or should I go? How the human brain manages the trade-off between exploitation and exploration. Philosophical Transactions of the Royal Society B: Biological Sciences, 362(1481), 933-942. https://doi.org/10.1098/rstb.2007.2098

Costa, V. D., Mitz, A. R., \& Averbeck, B. B. (2019). Subcortical Substrates of Explore-Exploit Decisions in Primates. Neuron, 103(3), 533-545.e5. https://doi.org/10.1016/j.neuron.2019.05.017

Costa, V. D., Tran, V. L., Turchi, J., \& Averbeck, B. B. (2014). Dopamine modulates novelty seeking behavior during decision making. Behavioral Neuroscience, 128(5), 556-566. https://doi.org/10.1037/a0037128

Cox, A., \& Fisher, M. (2009). The Texas billionaire's pregnant bride: An evolutionary interpretation of romance fiction titles. Journal of Social, Evolutionary, and Cultural Psychology, 3(4), 386-401. https://doi.org/10.1037/h0099308

Crowston, K., \& Fagnot, I. (2018). Stages of motivation for contributing user-generated content: A theory and empirical test. International Journal of Human-Computer Studies, 109, 89-101. https://doi.org/10.1016/j.ijhcs.2017.08.005

Cutting, J. E., Brunick, K. L., DeLong, J. E., Iricinschi, C., \& Candan, A. (2011). Quicker, Faster, Darker: Changes in Hollywood Film over 75 Years. I-Perception, 2(6), 569-576. https://doi.org/10.1068/i0441 aap

Damerius, L. A., Graber, S. M., Willems, E. P., \& van Schaik, C. P. (2017). Curiosity boosts orang-utan problem-solving ability. Animal Behaviour, 134, 57-70. https://doi.org/10.1016/j.anbehav.2017.10.005

Daugherty, T., Eastin, M. S., \& Bright, L. (2008). Exploring Consumer Motivations for Creating User-Generated Content. Journal of Interactive Advertising, 8(2), 16-25. 
https://doi.org/10.1080/15252019.2008.10722139

Daw, N. D., O’Doherty, J. P., Dayan, P., Seymour, B., \& Dolan, R. J. (2006). Cortical substrates for exploratory decisions in humans. Nature, 441(7095), 876-879. https://doi.org/10.1038/nature04766

de Courson, B., \& Baumard, N. (2019). Quantifying the Scientific Revolution [Preprint]. SocArXiv. https://doi.org/10.31235/osf.io/9ex8q

DeYoung, C. G. (2013). The neuromodulator of exploration: A unifying theory of the role of dopamine in personality. Frontiers in Human Neuroscience, 7. https://doi.org/10.3389/fnhum.2013.00762

DeYoung, C. G. (2015). Openness/intellect: A dimension of personality reflecting cognitive exploration. In M. Mikulincer, P. R. Shaver, M. L. Cooper, \& R. J. Larsen (Eds.), APA handbook of personality and social psychology, Volume 4: Personality processes and individual differences. (pp. 369-399). American Psychological Association. https://doi.org/10.1037/14343-017

Dubey, R., \& Griffiths, T. L. (2020). Reconciling novelty and complexity through a rational analysis of curiosity. Psychological Review, 127(3), 455-476. https://doi.org/10.1037/rev0000175

Dubourg, E. (2020a). La reconnaissance intuitive de la fiction [Application/xhtml+xml,application/pdf,online, database,application/xhtml+xml ; application/pdf]. 16 pages, pages 3550. https://doi.org/10.15122/ISBN.978-2-406-11008-8.P.0035

Dubourg, E. (2020b). La conquête de la fiction Harry Potter de J.-K. Rowling. Romanesques Revue du Cercll / Roman \& Romanesque 2020, n 12. Littérature de jeunesse et romanesque, 195-209. https://doi.org/10.15122/isbn.978-2-406-10636-4.p.0195

Dubourg, E., André, J.-B., \& Baumard, N. (2021a). L'origine des fictions: L'hypothèse des fonctions évolutionnaires sociales. Fabula.

Dubourg, E., André, J.-B., \& Baumard, N. (2021b). The evolution of music: One trait, many ultimate-level explanations. Commentary to 'Origins of music in credible signaling' by Mehr et al. Behavioral and Brain Sciences.

Dubourg, E., Thouzeau, V., de Dampierre, C., \& Baumard, N. (2021). Exploratory preferences explain the cultural success of imaginary worlds in modern societies. PsyArXiv. https://doi.org/10.31234/osf.io/d9uqs

Dunbar, R. (2017). Cognitive and Network Constraints in Real Life and Literature. In R. Kenna, M. MacCarron, \& P. MacCarron (Eds.), Maths Meets Myths: Quantitative Approaches to Ancient Narratives (pp. 7-19). Springer International Publishing. https://doi.org/10.1007/978-3-319-39445-9_2

Düzel, E., Bunzeck, N., Guitart-Masip, M., \& Düzel, S. (2010). NOvelty-related Motivation of Anticipation and exploration by Dopamine (NOMAD): Implications for healthy aging. Neuroscience \& Biobehavioral Reviews, 34(5), 660-669. https://doi.org/10.1016/j.neubiorev.2009.08.006

Eco, U. (1997). The role of the reader: Explorations in the semiotics of texts (First Midland Book ed. 1984, [Nachdr. ]). Indiana Univ. Pr.

Eliassen, S., Jørgensen, C., Mangel, M., \& Giske, J. (2007). Exploration or exploitation: Life expectancy changes the value of learning in foraging strategies. Oikos, 116(3), 513-523. https://doi.org/10.1111/j.2006.0030-1299.15462.x

Englerova, K., Klement, D., Frynta, D., Rokyta, R., \& Nekovarova, T. (2019). Reactions to novel 
objects in monkeys: What does it mean to be neophobic? Primates, 60(4), 347-353. https://doi.org/10.1007/s10329-019-00731-2

English, S., Fawcett, T. W., Higginson, A. D., Trimmer, P. C., \& Uller, T. (2016). Adaptive Use of Information during Growth Can Explain Long-Term Effects of Early Life Experiences. The American Naturalist, 187(5), 620-632. https://doi.org/10.1086/685644

Epstein, R. A., Patai, E. Z., Julian, J. B., \& Spiers, H. J. (2017). The cognitive map in humans: Spatial navigation and beyond. Nature Neuroscience, 20(11), 10.

Etchells, P. (2019). Lost in a good game: Why we play video games and what they can do for us. Icon Books Ltd.

Fagan, J. F. (1970). Memory in the infant. Journal of Experimental Child Psychology, 9(2), 217-226. https://doi.org/10.1016/0022-0965(70)90087-1

Falk, J. H., \& Balling, J. D. (2010). Evolutionary Influence on Human Landscape Preference. Environment and Behavior, 42(4), 479-493. https://doi.org/10.1177/0013916509341244

Fishelov, D. (1995). THE STRUCTURE OF GENERIC CATEGORIES: SOME COGNITIVE ASPECTS. Journal of Literary Semantics, 24(2). https://doi.org/10.1515/jlse.1995.24.2.117

FitzGibbon, L., Lau, J. K. L., \& Murayama, K. (2020). The seductive lure of curiosity: Information as a motivationally salient reward. Current Opinion in Behavioral Sciences, 35, 21-27. https://doi.org/10.1016/j.cobeha.2020.05.014

Frank, M. J., Doll, B. B., Oas-Terpstra, J., \& Moreno, F. (2009). Prefrontal and striatal dopaminergic genes predict individual differences in exploration and exploitation. Nature Neuroscience, 12(8), 1062-1068. https://doi.org/10.1038/nn.2342

Frankenhuis, W. E., Panchanathan, K., \& Nettle, D. (2016). Cognition in harsh and unpredictable environments. Current Opinion in Psychology, 7, 76-80. https://doi.org/10.1016/j.copsyc.2015.08.011

George, J. M., \& Zhou, J. (2001). When openness to experience and conscientiousness are related to creative behavior: An interactional approach. Journal of Applied Psychology, 86(3), 513 524. https://doi.org/10.1037/0021-9010.86.3.513

Gershman, S. J. (2018). Deconstructing the human algorithms for exploration. Cognition, 173, 34 42. https://doi.org/10.1016/j.cognition.2017.12.014

Gessey-Jones, T., Connaughton, C., Dunbar, R., Kenna, R., MacCarron, P., O’Conchobhair, C., \& Yose, J. (2020). Narrative structure of $A$ Song of Ice and Fire creates a fictional world with realistic measures of social complexity. Proceedings of the National Academy of Sciences, 202006465. https://doi.org/10.1073/pnas.2006465117

Gocłowska, M. A., Ritter, S. M., Elliot, A. J., \& Baas, M. (2019). Novelty seeking is linked to openness and extraversion, and can lead to greater creative performance. Journal of Personality, 87(2), 252-266. https://doi.org/10.1111/jopy.12387

Gopnik, A. (2020). Childhood as a solution to explore-exploit tensions. Philosophical Transactions of the Royal Society B: Biological Sciences, 375(1803), 20190502. https://doi.org/10.1098/rstb.2019.0502

Gopnik, A., Frankenhuis, W. E., \& Tomasello, M. (2020). Introduction to special issue: 'Life history and learning: how childhood, caregiving and old age shape cognition and culture in humans and other animals.' Philosophical Transactions of the Royal Society B: Biological Sciences, 375(1803), 20190489. https://doi.org/10.1098/rstb.2019.0489

Gopnik, A., Griffiths, T. L., \& Lucas, C. G. (2015). When Younger Learners Can Be Better (or at Least More Open-Minded) Than Older Ones. Current Directions in Psychological Science, 
24(2), 87-92. https://doi.org/10.1177/0963721414556653

Gopnik, A., O’Grady, S., Lucas, C. G., Griffiths, T. L., Wente, A., Bridgers, S., Aboody, R., Fung, H., \& Dahl, R. E. (2017). Changes in cognitive flexibility and hypothesis search across human life history from childhood to adolescence to adulthood. Proceedings of the National Academy of Sciences, 114(30), 7892-7899. https://doi.org/10.1073/pnas.1700811114

Gordon, G., Breazeal, C., \& Engel, S. (2015). Can Children Catch Curiosity from a Social Robot? Proceedings of the Tenth Annual ACM/IEEE International Conference on Human-Robot Interaction - HRI '15, 91-98. https:/ / doi.org/10.1145/2696454.2696469

Gottlieb, J., \& Oudeyer, P.-Y. (2018). Towards a neuroscience of active sampling and curiosity. Nature Reviews Neuroscience, 19(12), 758-770. https://doi.org/10.1038/s41583-018-00780

Gottlieb, J., Oudeyer, P.-Y., Lopes, M., \& Baranes, A. (2013). Information-seeking, curiosity, and attention: Computational and neural mechanisms. Trends in Cognitive Sciences, 17(11), 585593. https://doi.org/10.1016/j.tics.2013.09.001

Gottschall, J. (2012). The storytelling animal: How stories make us human. Houghton Mifflin Harcourt.

Gottschall, J., \& Wilson, D. S. (Eds.). (2005). The literary animal: Evolution and the nature of narrative. Northwestern University Press.

Gould, S. J. (2008). A Biological Homage to Mickey Mouse. Ecotone, 4(1-2), 333-340. https://doi.org/10.1353/ect.2008.0045

Gozli, D. G. (2018). Reaching Into the Unknown: Actions, Goal Hierarchies, and Explorative Agency. Frontiers in Psychology, 9, 6.

Grodal, T. (2010). High on Crime Fiction and Detection. Projections, 4(2). https://doi.org/10.3167/proj.2010.040205

Grodal, T. (2017). How film genres are a product of biology, evolution and culture-An embodied approach. Palgrave Communications, 3(1), 17079. https://doi.org/10.1057/palcomms.2017.79

Guarino, S., Yeater, D., Lacy, S., Dees, T., \& Hill, H. M. (2017). Responses to familiar and unfamiliar objects by belugas (Delphinapterus leucas), bottlenose dolphins (Tursiops truncatus), and Pacific white-sided dolphins (Lagenorhynchus obliquidens). Animal Cognition, 20(5), 823-827. https://doi.org/10.1007/s10071-017-1103-9

Gunderson, V. M., \& Sackett, G. P. (1984). Development of pattern recognition in infant pigtailed macaques (Macaca nemestrina). Developmental Psychology, 20(3), 418-426. https://doi.org/10.1037/0012-1649.20.3.418

Harris, P. L. (2000). The work of the imagination. Blackwell Publishers.

Hasson, U., Ghazanfar, A. A., Galantucci, B., Garrod, S., \& Keysers, C. (2012). Brain-to-brain coupling: A mechanism for creating and sharing a social world. Trends in Cognitive Sciences, 16(2), 114-121. https://doi.org/10.1016/j.tics.2011.12.007

Hayden, B., \& Niv, Y. (2020). The case against economic values in the brain [Preprint]. PsyArXiv. https://doi.org/10.31234/osf.io/7hgup

Healy, S., Dekort, S., \& Clayton, N. (2005). The hippocampus, spatial memory and food hoarding: A puzzle revisited. Trends in Ecology \& Evolution, 20(1), 17-22. https://doi.org/10.1016/j.tree.2004.10.006

Herzog, T. R. (1984). A cognitive analysis of preference for field-and-forest environments. Landscape Research, 9(1), 10-16. https://doi.org/10.1080/01426398408706092

Herzog, T. R. (1985). A cognitive analysis of preference for waterscapes. Journal of Environmental 
Psychology, 5(3), 225-241. https://doi.org/10.1016/S0272-4944(85)80024-4

Herzog, T. R., \& Bryce, A. G. (2007). Mystery and Preference in Within-Forest Settings. Environment and Behavior, 39(6), 779-796. https://doi.org/10.1177/0013916506298796

Herzog, T., \& Smith, G. A. (1988). Danger, Mystery, and Environmental Preference. Environment and Behavior, 20(3), 320-344. https://doi.org/10.1177/0013916588203004

Hewlett, B., van de Koppel, J. M. H., \& Cavalli-Sforza, L. L. (1982). Exploration Ranges of Aka Pygmies of the Central African Republic. Man, 17(3), 418. https://doi.org/10.2307/2801706

Hills, T. (2004). Dopamine and Glutamate Control Area-Restricted Search Behavior in Caenorhabditis elegans. Journal of Neuroscience, 24(5), 1217-1225. https://doi.org/10.1523/JNEUROSCI.1569-03.2004

Hills, T. T. (2006). Animal Foraging and the Evolution of Goal-Directed Cognition. Cognitive Science, 30(1), 3-41. https://doi.org/10.1207/s15516709cog0000_50

Hills, T. T., \& Stroup, W. (2004). Cognitive exploration and search behavior in the development of endogenous representations. American Educational Research Association, San Diego.

Hills, T. T., Todd, P. M., \& Goldstone, R. L. (2010). The central executive as a search process: Priming exploration and exploitation across domains. Journal of Experimental Psychology: General, 139(4), 590-609. https://doi.org/10.1037/a0020666

Hinde, R. A., \& Barden, L. A. (1985). The evolution of the teddy bear. Animal Behaviour, 33(4), 1371-1373. https://doi.org/10.1016/S0003-3472(85)80205-0

Horvitz, J. C., Stewart, T., \& Jacobs, B. L. (1997). Burst activity of ventral tegmental dopamine neurons is elicited by sensory stimuli in the awake cat. Brain Research, 759(2), 251-258. https://doi.org/10.1016/S0006-8993(97)00265-5

Hughes, R. N. (2007). Neotic preferences in laboratory rodents: Issues, assessment and substrates. Neuroscience \& Biobehavioral Reviews, 31(3), 441-464. https://doi.org/10.1016/j.neubiorev.2006.11.004

Humphreys, K. L., Lee, S. S., Telzer, E. H., Gabard-Durnam, L. J., Goff, B., Flannery, J., \& Tottenham, N. (2015). Exploration-exploitation strategy is dependent on early experience: Exploration-Exploitation. Developmental Psychobiology, 57(3), 313-321. https://doi.org/10.1002/dev.21293

Ikemi, M. (2005). The effects of mystery on preference for residential façades. Journal of Environmental Psychology, 25(2), 167-173. https://doi.org/10.1016/j.jenvp.2005.04.001

Jacobs, L. F. (2003). The Evolution of the Cognitive Map. Brain, Behavior and Evolution, 62(2), 128-139. https://doi.org/10.1159/000072443

Jacquet, P. O., Safra, L., Wyart, V., Baumard, N., \& Chevallier, C. (2019). The ecological roots of human susceptibility to social influence: A pre-registered study investigating the impact of early-life adversity. Royal Society Open Science, 6(1), 180454. https://doi.org/10.1098/rsos.180454

Jenkins, H. (2006). Convergence culture: Where old and new media collide. New York University Press. Jiang, Q. (2013). Translation and the Development of Science Fiction in Twentieth-Century China. Science-Fiction Studies. https://doi.org/10.5621/sciefictstud.40.1.0116

Jobling, I. (2001). The psychological foundations of the hero-ogre story: A cross-cultural study. Human Nature, 12(3), 247-272. https://doi.org/10.1007/s12110-001-1009-7

Jullier, L. (2018). Cinéma et psychologie cognitive: Le «tournant corporel» des études audiovisuelles. Ekphrasis. Images, Cinema, Theory, Media, 20(2), 20-34. 
https://doi.org/10.24193/ekphrasis.20.2

Kakade, S., \& Dayan, P. (2002). Dopamine: Generalization and bonuses. Neural Networks, $15(4$ 6), 549-559. https://doi.org/10.1016/S0893-6080(02)00048-5

Kaplan, H. S., Hooper, P. L., \& Gurven, M. (2009). The evolutionary and ecological roots of human social organization. Philosophical Transactions of the Royal Society B: Biological Sciences, 364(1533), 3289-3299. https://doi.org/10.1098/rstb.2009.0115

Kaplan, R., \& Kaplan, S. (1989). The experience of nature: A psychological perspective. Cambridge University Press.

Kaplan, S. (1987). Aesthetics, Affect, and Cognition: Environmental Preference from an Evolutionary Perspective. Environment and Behavior, 19(1), 3-32. https://doi.org/10.1177/0013916587191001

Kaplan, S. (1988). Perception and landscape: Conceptions and misconceptions. In J. L. Nasar (Ed.), Environmental Aesthetics (1st ed., pp. 45-55). Cambridge University Press. https://doi.org/10.1017/CBO9780511571213.006

Kidd, C., \& Hayden, B. Y. (2015). The Psychology and Neuroscience of Curiosity. Neuron, 88(3), 449-460. https://doi.org/10.1016/j.neuron.2015.09.010

Kidd, C., Piantadosi, S. T., \& Aslin, R. N. (2012). The Goldilocks Effect: Human Infants Allocate Attention to Visual Sequences That Are Neither Too Simple Nor Too Complex. PLoS ONE, 7(5), e36399. https://doi.org/10.1371/journal.pone.0036399

Kiverstein, J., Miller, M., \& Rietveld, E. (2019). The feeling of grip: Novelty, error dynamics, and the predictive brain. Synthese, 196(7), 2847-2869. https://doi.org/10.1007/s11229-0171583-9

Knutson, B., \& Cooper, J. C. (2006). The Lure of the Unknown. Neuron, 51(3), 280-282. https://doi.org/10.1016/j.neuron.2006.07.017

Korobkova, E., Emonet, T., Vilar, J. M. G., Shimizu, T. S., \& Cluzel, P. (2004). From molecular noise to behavioural variability in a single bacterium. Nature, 428(6982), 574-578. https://doi.org/10.1038/nature02404

Koster, R., Seow, T. X., Dolan, R. J., \& Düzel, E. (2016). Stimulus Novelty Energizes Actions in the Absence of Explicit Reward. PLOS ONE, 11(7), e0159120. https://doi.org/10.1371/journal.pone.0159120

Krebs, R. M., Schott, B. H., Schütze, H., \& Düzel, E. (2009). The novelty exploration bonus and

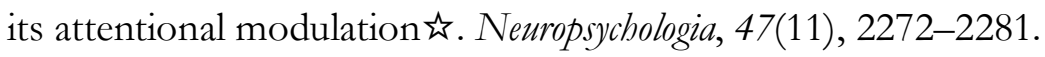
https://doi.org/10.1016/j.neuropsychologia.2009.01.015

Krueger, P. M., Wilson, R. C., \& Cohen, J. D. (2017). Strategies for exploration in the domain of losses. Judgment and Decision Making, 14.

Kuipers, G., \& de Kloet, J. (2009). Banal cosmopolitanism and The Lord of the Rings: The limited role of national differences in global media consumption. Poetics, 37(2), 99-118. https://doi.org/10.1016/j.poetic.2009.01.002

Le Heron, C., Kolling, N., Plant, O., Kienast, A., Janska, R., Ang, Y.-S., Fallon, S., Husain, M., \& Apps, M. A. J. (2019). Dopamine modulates dynamic decision-making during foraging [Preprint]. Neuroscience. https://doi.org/10.1101/709857

Lee, E. S. (1966). A THEORY OF MIGRATION. 12.

Li, W., Li, X., Huang, L., Kong, X., Yang, W., Wei, D., Li, J., Cheng, H., Zhang, Q., Qiu, J., \& Liu, J. (2014). Brain structure links trait creativity to openness to experience. 8.

Liquin, E. G., \& Lombrozo, T. (2020a). A functional approach to explanation-seeking curiosity. 
Cognitive Psychology, 119, 101276. https://doi.org/10.1016/j.cogpsych.2020.101276

Liquin, E. G., \& Lombrozo, T. (2020b). Explanation-seeking curiosity in childhood. Current Opinion in Behavioral Sciences, 35, 14-20. https://doi.org/10.1016/j.cobeha.2020.05.012

Louwerse, M. M., \& Benesh, N. (2012). Representing Spatial Structure Through Maps and Language: Lord of the Rings Encodes the Spatial Structure of Middle Earth. Cognitive Science, 36(8), 1556-1569. https://doi.org/10.1111/cogs.12000

Lucas, C. G., Bridgers, S., Griffiths, T. L., \& Gopnik, A. (2014). When children are better (or at least more open-minded) learners than adults: Developmental differences in learning the forms of causal relationships. Cognition, 131(2), 284-299. https://doi.org/10.1016/j.cognition.2013.12.010

Lucian of Samosata. (150 C.E.). True history.

MacDonald, D. H., \& Hewlett, B. S. (1999). Reproductive Interests and Forager Mobility. Current Anthropology, 40(4), 501-524. https://doi.org/10.1086/200047

Manning, P. (2017). The Maddison Project: Historical GDP Estimates Worldwide. Journal of World-Historical Information. https://doi.org/10.5195/jwhi.2017.46

Mar, R. A. (2018). Evaluating whether stories can promote social cognition: Introducing the Social Processes and Content Entrained by Narrative (SPaCEN) framework. Discourse Processes, 55(5-6), 454-479. https://doi.org/10.1080/0163853X.2018.1448209

Mar, R. A., \& Oatley, K. (2008). The Function of Fiction is the Abstraction and Simulation of Social Experience. Perspectives on Psychological Science, 3(3), 173-192. https://doi.org/10.1111/j.1745-6924.2008.00073.x

Mar, R. A., Oatley, K., Hirsh, J., dela Paz, J., \& Peterson, J. B. (2006). Bookworms versus nerds: Exposure to fiction versus non-fiction, divergent associations with social ability, and the simulation of fictional social worlds. Journal of Research in Personality, 40(5), 694-712. https://doi.org/10.1016/j.jrp.2005.08.002

Martins, M. de J. D., \& Baumard, N. (2020). The rise of prosociality in fiction preceded democratic revolutions in Early Modern Europe. Proceedings of the National Academy of Sciences, 202009571. https://doi.org/10.1073/pnas.2009571117

Maspons, J., Molowny-Horas, R., \& Sol, D. (2019). Behaviour, life history and persistence in novel environments. Philosophical Transactions of the Royal Society B: Biological Sciences, 374(1781), 20180056. https://doi.org/10.1098/rstb.2018.0056

McCrae, R. R. (1993). Openness to Experience as a Basic Dimension of Personality. Imagination, Cognition and Personality, 13(1), 39-55. https://doi.org/10.2190/H8H6-QYKR-KEU8GAQ0

McDevitt, M. A., Pisklak, J. M., Spetch, M., \& Dunn, R. (2018). The influence of outcome delay on suboptimal choice. Behavioural Processes, 157, 279-285. https://doi.org/10.1016/j.beproc.2018.10.008

Mehr, S. A., Krasnow, M., Bryant, G. A., \& Hagen, E. H. (2020). Origins of music in credible signaling [Preprint]. PsyArXiv. https://doi.org/10.31234/osf.io/nrqb3

Mell, H., Baumard, N., \& André, J.-B. (2019). Time is money. Waiting costs explain why selection favors steeper time discounting in deprived environments. [Preprint]. EcoEvoRxiv. https://doi.org/10.32942/osf.io/7d56s

Menadue, C. B., \& Jacups, S. (2018). Who Reads Science Fiction and Fantasy, and How Do They Feel About Science? Preliminary Findings From an Online Survey. SAGE Open, 8(2), 215824401878094. https://doi.org/10.1177/2158244018780946 
Meneghetti, C., Grimaldi, F., Nucci, M., \& Pazzaglia, F. (2020). Positive and Negative Wayfinding Inclinations, Choice of Navigation Aids, and How They Relate to Personality Traits. Journal of Individual Differences, 41(1), 45-52. https:/ / doi.org/10.1027/1614$0001 / \mathrm{a} 000302$

Mettke-Hofmann, C., Winkler, H., \& Leisler, B. (2002). The Significance of Ecological Factors for Exploration and Neophobia in Parrots. Ethology, 108(3), 249-272. https://doi.org/10.1046/j.1439-0310.2002.00773.x

Miller, G. (2001). The mating mind: How sexual choice shaped the evolution of human nature. Anchor Books.

Miner, E. J., Gurven, M., Kaplan, H., \& Gaulin, S. J. C. (2014). Sex difference in travel is concentrated in adolescence and tracks reproductive interests. Proceedings of the Royal Society B: Biological Sciences, 281(1796), 20141476. https://doi.org/10.1098/rspb.2014.1476

Montello, D. R. (2005). Navigation. In P. Shah \& A. Miyake (Eds.), The Cambridge Handbook of Visuospatial Thinking (1st ed., pp. 257-294). Cambridge University Press. https://doi.org/10.1017/CBO9780511610448.008

Morgan, T. J. H., Suchow, J. W., \& Griffiths, T. L. (2020). Experimental evolutionary simulations of learning, memory and life history. Philosophical Transactions of the Royal Society B: Biological Sciences, 375(1803), 20190504. https://doi.org/10.1098/rstb.2019.0504

Morin, O. (2016). Reasons to be fussy about cultural evolution. Biology \& Philosophy, 31(3), 447458. https://doi.org/10.1007/s10539-016-9516-4

Morin, O., Acerbi, A., \& Sobchuk, O. (2019). Why people die in novels: Testing the ordeal simulation hypothesis. Palgrave Communications, 5(1), 62. https://doi.org/10.1057/s41599-0190267-0

Muffato, V., Meneghetti, C., \& De Beni, R. (2016). Not all is lost in older adults' route learning: The role of visuo-spatial abilities and type of task. Journal of Environmental Psychology, 47, 230-241. https://doi.org/10.1016/j.jenvp.2016.07.003

Muffato, V., Toffalini, E., Meneghetti, C., Carbone, E., \& De Beni, R. (2017). Individual visuospatial factors and familiar environment knowledge: A structural equation modeling analysis. Personality and Individual Differences, 113, 96-102. https://doi.org/10.1016/j.paid.2017.03.023

Nave, G., Rentfrow, J., \& Bhatia, S. (2020). We Are What We Watch: Movie Plots Predict the Personalities of Those who "Like" Them [Preprint]. PsyArXiv. https://doi.org/10.31234/osf.io/wsdu8

Neidhardt, F. C., \& Curtiss, R. (Eds.). (1996). Escherichia coli and Salmonella: Cellular and molecular biology (2nd ed). ASM Press.

Nettle, D. (2005a). The Wheel of Fire and the Mating Game: Explaining the Origins of Tragedy and Comedy. Journal of Cultural and Evolutionary Psychology, 3(1), 39-56. https://doi.org/10.1556/JCEP.3.2005.1.3

Nettle, D. (2005b). Exploring the psychological foundations of drama. In J. Gottschall \& D. S. Wilson (Eds.), The Literary Animal: Evolution and the Nature of Narrative. Northwestern University Press. https://doi.org/10.2307/j.ctvw1d5h1

Nettle, D. (2019). State-dependent cognition and its relevance to cultural evolution. Behavioural Processes, 161, 101-107. https://doi.org/10.1016/j.beproc.2018.01.018

Omar, B., \& Dequan, W. (2020). Watch, Share or Create: The Influence of Personality Traits and User Motivation on TikTok Mobile Video Usage. International Journal of Interactive Mobile 
Technologies (IJIM), 14(04), 121. https://doi.org/10.3991/ijim.v14i04.12429

Oudeyer, P.-Y., Gottlieb, J., \& Lopes, M. (2016). Intrinsic motivation, curiosity, and learning. In Progress in Brain Research (Vol. 229, pp. 257-284). Elsevier.

https://doi.org/10.1016/bs.pbr.2016.05.005

Panksepp, J. (2005). Affective neuroscience: The foundations of human and animal emotions. Oxford Univ. Press.

Pavel, T. G. (2017). Univers de la fiction: Postface inédite.

Pazzaglia, F., Meneghetti, C., \& Ronconi, L. (2018). Tracing a Route and Finding a Shortcut: The Working Memory, Motivational, and Personality Factors Involved. Frontiers in Human Neuroscience, 12, 225. https://doi.org/10.3389/fnhum.2018.00225

Peeler, D. F., \& Nowakowski, R. S. (1987). Genetic factors and the measurement of exploratory activity. Behavioral and Neural Biology, 48(1), 90-103. https://doi.org/10.1016/S01631047(87)90619-4

Pinker, S. (1997). How the mind works (Norton pbk). Norton.

Pinker, S. (2007). Toward a Consilient Study of Literature. Philosophy and Literature, 31(1), 162 178. https://doi.org/10.1353/phl.2007.0016

Platt, M. L., \& Brannon, E. M. (1996). Differences in feeding ecology predict differences in perfonnance between golden lion tamarins (Leontopithecus rosalia) and Wied's mannosets (Callithrix kubli) on spatial and visual memory tasks. 10.

Poch, R., \& Martin, B. (2015). Effects of intrinsic and extrinsic motivation on user-generated content. Journal of Strategic Marketing, 23(4), 305-317. https://doi.org/10.1080/0965254X.2014.926966

Polizzi di Sorrentino, E., Sabbatini, G., Truppa, V., Bordonali, A., Taffoni, F., Formica, D., Baldassarre, G., Mirolli, M., Guglielmelli, E., \& Visalberghi, E. (2014). Exploration and learning in capuchin monkeys (Sapajus spp.): The role of action-outcome contingencies. Animal Cognition, 17(5), 1081-1088. https://doi.org/10.1007/s10071-014-0740-5

Poor, N. (2014). Computer game modders' motivations and sense of community: A mixed-methods approach. New Media \& Society, 16(8), 1249-1267. https://doi.org/10.1177/1461444813504266

Purhonen, S., Gronow, J., \& Rahkonen, K. (2009). Social differentiation of musical and literary taste patterns in Finland. Research on Finnish Society, 2, 39-49.

Reed, P., \& Adams, L. (1996). Influence of Salient Stimuli on Rats' Performance in an Eight-Arm Radial Maze. Learning and Motivation, 27(3), 294-306. https://doi.org/10.1006/lmot.1996.0016

Reed, P., Mitchell, C., \& Nokes, T. (1996). Intrinsic reinforcing properties of putatively neutral stimuli in an instrumental two-lever discrimination task. Animal Learning \& Behavior, 24(1), 38-45. https://doi.org/10.3758/BF03198952

Rojas-Ferrer, I., Thompson, M. J., \& Morand-Ferron, J. (2020). Is exploration a metric for information gathering? Attraction to novelty and plasticity in black-capped chickadees. Ethology, 126(4), 383-392. https://doi.org/10.1111/eth.12982

Root-Bernstein, M. (2013). The Creation of Imaginary Worlds. In M. Taylor, The Oxford Handbook of the Development of Imagination (Oxford University Press, pp. 417-437).

Root-Bernstein, M. (2014). Inventing imaginary worlds: From childhood play to adult creativity across the arts and sciences. Rowman \& Littlefield Education.

Root-Bernstein, M., \& Root-Bernstein, R. (2006). Imaginary Worldplay in Childhood and 
Maturity and Its Impact on Adult Creativity. Creativity Research Journal, 18(4), 405-425. https://doi.org/10.1207/s15326934crj1804_1

Rosati, A. G., \& Hare, B. (2012). Chimpanzees and bonobos exhibit divergent spatial memory development: Spatial memory development in chimpanzees and bonobos. Developmental Science, 15(6), 840-853. https://doi.org/10.1111/j.1467-7687.2012.01182.x

Rosati, A. G., Rodriguez, K., \& Hare, B. (2014). The ecology of spatial memory in four lemur species. Animal Cognition, 17(4), 947-961. https://doi.org/10.1007/s10071-014-0727-2

Rubenstein, J. (1967). Maternal Attentiveness and Subsequent Exploratory Behavior in the Infant. Child Development, 38(4), 1089. https://doi.org/10.2307/1127106

Ruso, B., Renninger, L., \& Atzwanger, K. (2003). Human Habitat Preferences: A Generative Territory for Evolutionary Aesthetics Research. In E. Voland \& K. Grammer (Eds.), Evolutionary Aesthetics (pp. 279-294). Springer Berlin Heidelberg. https://doi.org/10.1007/978-3-662-07142-7_10

Ryan, M.-L. (1991). Possible worlds, artificial intelligence, and narrative theory. Indiana University Press.

Ryan, M.-L. (2014). Space. The Living Handbook of Narratology. http://www.lhn.uni-hamburg.de/article/space

Saad, G. (2012). Nothing in Popular Culture Makes Sense except in the Light of Evolution. Review of General Psychology, 16(2), 109-120. https://doi.org/10.1037/a0027906

Safra, L., Chevallier, C., Grèzes, J., \& Baumard, N. (2020). Tracking historical changes in trustworthiness using machine learning analyses of facial cues in paintings. Nature Communications, 11(1), 4728. https:// doi.org/10.1038/s41467-020-18566-7

Saler, M. T. (2012). As if: Modern enchantment and the literary pre-history of virtual reality. Oxford University Press.

Salmon, C., \& Symons, D. (2004). Slash fiction and human mating psychology. Journal of Sex Research, 41(1), 94-100. https://doi.org/10.1080/00224490409552217

Schaeffer, J.-M. (1999). Pourquoi la fiction? Seuil.

Scholes, R., \& Rabkin, E. S. (1977). Science fiction: History, science, vision. Oxford University Press.

Schultz, W. (1998). Predictive Reward Signal of Dopamine Neurons. Journal of Neurophysiology, 80(1), 1-27. https://doi.org/10.1152/jn.1998.80.1.1

Schultz, W. (2015). Neuronal Reward and Decision Signals: From Theories to Data. Physiological Reviews, 95(3), 853-951. https://doi.org/10.1152/physrev.00023.2014

Schulz, E., \& Gershman, S. J. (2019). The algorithmic architecture of exploration in the human brain. Current Opinion in Neurobiology, 55, 7-14. https://doi.org/10.1016/j.conb.2018.11.003

Scott-Phillips, T., Blancke, S., \& Heintz, C. (2018). Four misunderstandings about cultural attraction. Evolutionary Anthropology: Issues, News, and Reviews, 27(4), 162-173. https://doi.org/10.1002/evan.21716

Searle, J. R. (1975). The Logical Status of Fictional Discourse. New Literary History, 6(2), 319. https://doi.org/10.2307/468422

Sibley, C. G., \& Duckitt, J. (2008). Personality and Prejudice: A Meta-Analysis and Theoretical Review. Personality and Social Psychology Review, 12(3), 248-279. https://doi.org/10.1177/1088868308319226

Silvey, R., \& MacKeith, S. (1988). The paracosm: A special form of fantasy. In Organizing early experience: Imagination and cognition in childhood.

Singh, M. (2019). The evolutionary and psychological foundations of universal narrative structure [Preprint]. 
Open Science Framework. https://doi.org/10.31219/osf.io/p8q7a

Singh, M. (2020). Subjective selection and the evolution of complex culture. 21.

Skolnick, D., \& Bloom, P. (2006). What does Batman think about SpongeBob? Children's understanding of the fantasy/fantasy distinction. Cognition, 101(1), B9-B18. https://doi.org/10.1016/j.cognition.2005.10.001

Snell-Rood, E., \& Snell-Rood, C. (2020). The developmental support hypothesis: Adaptive plasticity in neural development in response to cues of social support. Philosophical Transactions of the Royal Society B: Biological Sciences, 375(1803), 20190491. https://doi.org/10.1098/rstb.2019.0491

Sol, D., Sayol, F., Ducatez, S., \& Lefebvre, L. (2016). The life-history basis of behavioural innovations. Philosophical Transactions of the Royal Society B: Biological Sciences, 371(1690), 20150187. https://doi.org/10.1098/rstb.2015.0187

Song, H. (2013). Chinese Science Fiction: A Response to Modernization. Science Fiction Studies. https://doi.org/10.5621/SCIEFICTSTUD.40.1.0015

Sotamaa, O. (2010). When the Game Is Not Enough: Motivations and Practices Among Computer Game Modding Culture. Games and Culture, 5(3), 239-255. https://doi.org/10.1177/1555412009359765

Sperber, D. (1996). Explaining culture: A naturalistic approach. Blackwell.

Sperber, D., \& Hirschfeld, L. A. (2004). The cognitive foundations of cultural stability and diversity. Trends in Cognitive Sciences, 8(1), 40-46. https://doi.org/10.1016/j.tics.2003.11.002

Sperber, D., \& Wilson, D. (1987). Précis of Relevance: Communication and Cognition. Behavioral and Brain Sciences, 10(04), 697. https://doi.org/10.1017/S0140525X00055345

Spivey, J., Barrett, D., Padilla, E., \& Gonzalez-Lima, F. (2008). Mother-infant separation leads to hypoactive behavior in adolescent Holtzman rats. Behavioural Processes, 79(1), 59-65. https://doi.org/10.1016/j.beproc.2008.05.002

Stansfield, K. H., \& Kirstein, C. L. (2006). Effects of novelty on behavior in the adolescent and adult rat. Developmental Psychobiology, 48(1), 10-15. https://doi.org/10.1002/dev.20127

Stevens, J. R., Rosati, A. G., Ross, K. R., \& Hauser, M. D. (2005). Will Travel for Food: Spatial Discounting in Two New World Monkeys. Current Biology, 15(20), 1855-1860. https://doi.org/10.1016/j.cub.2005.09.016

Sugiyama, S. (1996). On the origins of narrative: Storyteller bias as a fitness-enhancing strategy. Human Nature, 7(4), 403-425. https://doi.org/10.1007/BF02732901

Sugiyama, S. (2001). Food, foragers, and folklore: The role of narrative in human subsistence. Evolution and Human Behavior, 22(4), 221-240. https://doi.org/10.1016/S10905138(01)00063-0

Sun, Y., Dong, X., \& McIntyre, S. (2017). Motivation of User-Generated Content: Social Connectedness Moderates the Effects of Monetary Rewards. Marketing Science, 36(3), 10.

Sutton, R. S. (1990). Integrated Architectures for Learning, Planning, and Reacting Based on Approximating Dynamic Programming. In Machine Learning Proceedings 1990 (pp. 216-224). Elsevier. https://doi.org/10.1016/B978-1-55860-141-3.50030-4

Tan, E. S. (2018). A psychology of the film. Palgrave Communications, 4(1), 82. https://doi.org/10.1057/s41599-018-0111-y

Taylor, M., Mottweiler, C. M., Aguiar, N. R., Naylor, E. R., \& Levernier, J. G. (2020). Paracosms: The Imaginary Worlds of Middle Childhood. Child Development, 91(1). https://doi.org/10.1111/cdev.13162 
Todorov, T. (2015). Introduction à la littérature fantastique. Éditions du Seuil.

Tolkien, J. R. R., \& Tolkien, C. (2006). The monsters and the critics and other essays. HarperCollins.

Tooby, J., \& Cosmides, L. (1992). The Psychological Foundations of Culture. 72.

Ulrich, R. S. (1979). Visual landscapes and psychological well-being. Landscape Research, 4(1), 1723. https://doi.org/10.1080/01426397908705892

van Schaik, C. P., Burkart, J., Damerius, L., Forss, S. I. F., Koops, K., van Noordwijk, M. A., \& Schuppli, C. (2016). The reluctant innovator: Orangutans and the phylogeny of creativity. Philosophical Transactions of the Royal Society B: Biological Sciences, 371(1690), 20150183. https://doi.org/10.1098/rstb.2015.0183

Vanderbeke, D. (2019). On Love and Marriage in Popular Genres. In D. Vanderbeke \& B. Cooke (Eds.), Evolution and Popular Narrative. Brill | Rodopi. https://doi.org/10.1163/9789004391161_006

Veblen, T. (1899). Theory of the leisure class (New ed).

Verpooten, J., \& Nelissen, M. (2010). Sensory exploitation and cultural transmission: The late emergence of iconic representations in human evolution. Theory in Biosciences, 129(2-3), 211-221. https://doi.org/10.1007/s12064-010-0095-7

Wade, S., \& Kidd, C. (2019). The role of prior knowledge and curiosity in learning. Psychonomic Bulletin \& Review, 26(4), 1377-1387. https:/ / doi.org/10.3758/s13423-019-01598-6

Walton, K. L. (1993). Mimesis as make-believe: On the foundations of the representational arts. Harvard University Press.

Wang, M. Z., \& Hayden, B. Y. (2019). Monkeys are curious about counterfactual outcomes. Cognition, 189, 1-10. https://doi.org/10.1016/j.cognition.2019.03.009

Weisberg, S. M., Schinazi, V. R., Newcombe, N. S., Shipley, T. F., \& Epstein, R. A. (2014). Variations in cognitive maps: Understanding individual differences in navigation. Journal of Experimental Psychology: Learning, Memory, and Cognition, 40(3), 669-682. https://doi.org/10.1037/a0035261

Wilson, D. (2018). Relevance theory and literary interpretation. In T. Cave \& D. Wilson (Eds.), Reading beyond the code: Literature and relevance theory (First edition). Oxford University Press.

Wilson, R. C., Geana, A., White, J. M., Ludvig, E. A., \& Cohen, J. D. (2014). Humans use directed and random exploration to solve the explore-exploit dilemma. Journal of Experimental Psychology: General, 143(6), 2074-2081. https://doi.org/10.1037/a0038199

Wolf, M. J. P. (2013). Building imaginary worlds: The theory and history of subcreation. Routledge.

Zajonc, R. B. (1980). Feeling and thinking: Preferences need no inferences. American Psychologist, 35(2), 151-175. https://doi.org/10.1037/0003-066X.35.2.151 